\title{
EL ART. 155 \\ DE LA CONSTITUCIÓN ESPAÑOLA (EL ACUERDO DEL SENADO)
}

JOSÉ M. ${ }^{a}$ LAFUENTE BALLE 
SUMARIO

1. EL REQUERIMIENTO DEL GOBIERNO Y LA RESOLUCIÓN DEL SENADO DEL 27 DE OCTUBRE DE 2017. CRONOLOGÍA DE LOS ACONTECIMIENTOS; 2. LA APLICACIÓN DE LA COERCIÓN ESTATAL DEL ART. 155 EN CATALUÑA. LA POLARIZACIÓN DEL ELECTORADO; 3. LA CUESTIÓN PROCESAL DE LA RECURRIBILIDAD DEL ACUERDO DEL SENADO; 4. EL RECURSO DE INCONSTITUCIONALIDAD DE UNIDOS-PODEMOS; 5. EL DICTAMEN 14/2017 DEL CONSELL DE GARANTIES ESTATUTÁRIES. EL RECURSO DE INCONSTITUCIONALIDAD DEL PARLAMENTO DE CATALUÑA; 6. LA CUESTIÓN MATERIAL: ¿CONSTITUYE EL BLOQUE DE CONSTITUCIONALIDAD UN LÍMITE AL ART. 155?EXTRAPOLAR LA DOCTRINA DE LA DISCRECIONALIDAD DEL GOBIERNO EN EL ART. 86 C. E. 


\title{
EL ART. 155 \\ DE LA CONSTITUCIÓN ESPAÑOLA (EL ACUERDO DEL SENADO)
}

\author{
JOSÉ M. ${ }^{\mathrm{a}}$ LAFUENTE BALLE ${ }^{1}$ \\ Profesor titular de Derecho Constitucional \\ Universidad de Girona
}

\section{EL REQUERIMIENTO DEL GOBIERNO Y LA RESOLUCIÓN DEL SENADO DEL 27 DE OCTUBRE DE 2017. CRONOLOGÍA DE LOS ACONTECIMIENTOS}

El procedimiento de la coerción estatal a una Comunidad autónoma que establece el art. 155 es, conforme a la cita del prof. Cruz Villalón ${ }^{2}$, «la decisión más trascendente de las previstas en la Constitución». Acorde a la gravedad de su objeto (la desobediencia o el atentado contra la seguridad nacional), los trámites responden a la prudencia y cuidan de asegurar todas las garantías.

El requisito del previo requerimiento al Presidente de la Comunidad Autónoma que establece el art. 55 se cumplimentó con la carta que el Presidente del Gobierno central dirigió el 11 de octubre de 2017 al Presidente de la Generalitat ${ }^{3}$ y en la que se le insta a responder a la siguiente cuestión:

«Si alguna autoridad de la Generalitat de Cataluña ha declarado la independencia de Cataluña y/o si su declaración del 10 de octubre de 2017 ante el pleno del Parlamento implica la declaración de independencia al margen de que esta se encuentre en vigor o no».

Así, el Gobierno pide que se le comunique la respuesta antes de las 10:00 horas del 16 de octubre. En el caso de que las respuestas sean afirmativa, no conteste, o dé otro tipo de contestación que no sea un «sí» o un «no», se le requiere para que

${ }^{1}$ José M. $^{\mathrm{a}}$ LAFUENTE BALLE. Profesor titular Derecho Constitucional. Universidad de Girona. Facultad de Derecho. Campus Montilivi. 17003 - GIRONA. Email: josep.lafuente@udg.edu

2 Pedro CRUZ VILLALÓN (1981): «La protección extraordinaria del Estado» en Alberto Predieri y Eduardo García de Enterría, La Constitución española de 1978. Ed. Civitas, Madrid, p. 715.

3 http://www.lamoncloa.gob.es/consejodeministros/Documents/11102017-requerimiento.pdf 
«revoque u ordene la revocación de dicha declaración de independencia a fin de restaurar el orden constitucional y estatuario, ordenando el cese de cualquier actuación dirigida a la promoción, avance o culminación del denominado proceso constituyente».

Por su parte, el Presidente de la Generalitat Carles Puigdemont contestó el mismo día 16 de octubre ${ }^{4}$ en los siguientes términos:

«En este sentido, me sorprendió que en su escrito del pasado 11 de octubre anunciara la voluntad de su gobierno de poner en marcha el artículo 155 de la Constitución para suspender el autogobierno de Cataluña. Cuando el pasado día 10, atendiendo a la petición de numerosas personalidades e instituciones internacionales, españolas y catalanas, le planteé una oferta sincera de diálogo, no lo bice como una demostración de debilidad sino como una propuesta bonesta para encontrar una solución entre el Estado español y Cataluña que lleva bloqueada desde hace muchos años.»

Esta respuesta mereció la réplica del Presidente Mariano Rajoy ${ }^{5}$

«Ciertamente, el requerimiento que yo le envié supone el paso previo al procedimiento establecido en el art. 155 de la Constitución que, en contra de lo que usted afirma, no implica la suspensión del autogobierno, sino la restauración de la legalidad en la autonomía. Pero, ante todo, el requerimiento es una oportunidad para reconducir el grave deterioro de la convivencia que se vive en Cataluña, para que la Generalitat vuelva a la ley y, a partir de ahí, se recupere la normalidad institucional entre administraciones. La vuelta de la legalidad, previa para cualquier diálogo democrático, se refiere al orden constitucional pero también al Estatuto de Autonomía de Cataluña y sus normas de desarrollo, que han resultado gravemente lesionados por las actuaciones de su Gobierno en las últimas semanas (...). Le recuerdo, una vez más, que aún tiene margen para contestar de forma clara y sencilla al requerimiento que le remití el pasado miércoles. Sigue estando en su mano abrir un nuevo periodo de normalidad y lealtad institucional que todo el mundo le está reclamando. En caso contrario, será Usted el único responsable de la aplicación de la Constitución».

Por último, el Presidente de la Generalitat duplicó mediante carta de 19 de octubre de $2017^{6}$ en términos quizás aún más rotundos:

«Esta suspensión (de los efectos del mandato popular resultante del referéndum del 1 de octubre) continua vigente. La decisión de aplicar el artículo 155 corresponde al Gobierno del Estado, previa autorización del Senado. Pese a todos estos esfuerzos y nuestra voluntad de diálogo, que la única respuesta sea la suspensión de la autonomía, indica que no se es consciente del problema y que no se quiere hablar. Finalmente, si el Gobierno del Estado persiste en impedir el diálogo y continuar la represión, el Parlament de Cataluña podrá proceder, si lo estima oportuno, a votar la declaración formal de independencia que no votó el día 10 de octubre.»

\footnotetext{
${ }^{4}$ http://file02.lavanguardia.com/2017/10/16/55091641480-url.pdf

${ }^{5}$ http://www.lamoncloa.gob.es/presidente/actividades/Paginas/2017/161017 respuestarajoy.aspx

6 http://estaticos.elperiodico.com/resources/pdf/9/4/1508399971849.pdf? $\mathrm{ga}=2.52800495 .692215481 .1514812219-238778352.1478344253$
} 
En sesión del 21 de octubre de 2017 el Consejo de Ministros acordó las medidas que en aplicación del art. 155 se proponían al Senado que, con algunas modificaciones, fueron aprobadas en sesión de 27 de octubre de 2017. Es un largo texto en el que se enumeran los antecedentes; se da cuenta de la cumplimentación del previo requisito del requerimiento al Presidente autonómico; se explicitan los objetivos; y se relacionan las medidas que se estructuran según sus destinatarios: El Presidente de la Generalitat, su Vicepresidente y sus consejeros; la Administración en sus diferentes áreas de seguridad y orden público, tributos y presupuestos, comunicaciones electrónicas y audiovisuales; y el Parlamento cuya disolución se prevé antes de seis meses. Por último, concluye con ciertas medidas de carácter transversal. Este acuerdo fue definitivamente publicado en el B.O.E. del viernes 27 de octubre de 2017 como Orden/PRA 1034/2017.

A) El art. 155 como garantía del cumplimiento de las obligaciones constitucionales por los entes territoriales en los Estados compuestos. Glosa la Jurisprudencia del Tribunal Constitucional sobre el art. 155 (SSTC 215/2014, 4/1981, 25/1981, 49/1988). Analiza su equiparación con preceptos semejantes en el Derecho Constitucional comparado: arts. 37 de la Ley Fundamental de Bonn, 52 de la Constitución helvética, 100 de la Constitución austríaca, 125 de la Constitución italiana, 238 de la Constitución portuguesa, 4.4 de la Constitución de los Estados Unidos de América. Y recuerda el precedente del requerimiento en 1989 al Presidente de la Comunidad Autónoma de Canarias.

B) Cumplimiento de los presupuestos habilitantes para la aplicación del artículo 155 de la Constitución.

Se centra en el proceso soberanista de secesión objeto del Acuerdo que describe como una «desobediencia rebelde sistemática y consciente de los reiterados pronunciamientos y requerimientos del Tribunal Constitucional, afectando de manera grave al interés general de España», al pretender situar a la Comunidad Autónoma como un ente soberano en manifiesta negación del art. 1.2 de la Constitución y del propio Estatuto de Autonomía.

Se refiere a las Leyes del Parlament de Cataluña 19/2017 del referéndum de autodeterminación y 20/2017 de transitoriedad jurídica y fundacional de la República, que fueron aprobadas con vulneración del Reglamento parlamentario y haciendo caso omiso de las resoluciones del Tribunal Constitucional que procedió a su inmediata suspensión.

Tampoco los requerimientos del Consejo de Ministros sirvieron para la rectificación del President de la Generalitat que respondió afirmando que «el pueblo de Cataluña, el día 1 de octubre, decidió la independencia en un referéndum...».

Describe el deterioro del bienestar social y económico en Cataluña, la fractura de la convivencia, el traslado de domicilio social acordado por 
miles de empresas, la desaceleración de la actividad turística, industrial y comercial.

C) Requerimiento previo.

Reproduce el requerimiento del Consejo de Ministros de 11 de octubre de 2017 para que el President de Cataluña conteste si ha declarado la independencia y en tal caso revoque esa declaración y restaure el orden constitucional y estatutario dando cuenta a la Presidenta y la Mesa del Parlament.

Da cuenta de que en las dos cartas de respuesta cursadas por el Presidente Puigdemont el 16 y el 19 de octubre, lejos de atender al requerimiento, contestó afirmando que «el pueblo de Cataluña, el día 1 de octubre, decidió la independencia en un referéndum...».

D) Objetivo y necesidad de las medidas del artículo 155

Enumera cuatro objetivos:

— Restaurar la legalidad constitucional y estatutaria: «Cumplir la Ley es y ha de ser una obligación que vincula especialmente a los responsables y representantes públicos»

- Asegurar la neutralidad institucional: «la Generalitat ha obviado el interés general de los catalanes en favor del ideario independentista de una parte de ellos...»

- Mantener el bienestar social y el crecimiento económico: «La pretendida independencia de Cataluña implicaría asilar una economía que hoy está plenamente integrada en España, en la U.E. y en el mundo. Supondría su aislamiento de los flujos financieros, de capitales y Comerciales. Esto llevaría a un empobrecimiento de la economía de Cataluña entre el $25 \%$ y el $30 \%$, resultando una coyuntura económica insostenible»

- Asegurar los derechos y libertades de todos los catalanes: «Resulta esencial garantizar íntegramente esos derechos y proteger, especialmente, la libertad, la Seguridad y la pluralidad que son consustanciales a un Estado de Derecho...»

Por lo que se refiere a la necesidad de las medidas, el Acuerdo afirma que son las «absolutamente necesarias y proporcionadas» puesto que «de ningún modo tienen por objetivo suspender la autonomía de Cataluña, sino precisamente salvaguardar y restaurar la aplicación de su Estatuto de Autonomía como parte del orden constitucional». Advierte que la magnitud del incumplimiento determina que «no baste con la impartición de instrucciones a las autoridades autonómicas, ni tan siquiera con la asunción puntual de competencias», sino que se hace «imprescindible la sustitución en el ejercicio de las funciones de esos órganos». Y concluye aseverando «que las medidas cuya autorización se solicita se antojan imprescindibles, no solo para mantener la cohesión interna del Estado Español, sino para preservar de igual modo la posición de España en el exterior, tanto en la Unión Europea, el Consejo de Europa y las Naciones Unidas» 
Mediante Resolución de 27 de octubre de 2017 el Senado aprobó las medidas requeridas por el Gobierno que se estructuraron en los siguientes 5 apartados:

A) Medidas dirigidas al Presidente de la Generalitat de Cataluña, al Vicepresidente y al Consejo de Gobierno

Se cesan a todos estos altos cargos y se atribuye el Gobierno central el ejercicio de sus funciones. Así mismo se faculta al Presidente del Gobierno para disolver el Parlament y convocar elecciones autonómicas en el plazo máximo de seis meses.

B) Medidas dirigidas a la Administración de la Generalitat.

Se declara que la Administración de la Generalitat de Cataluña continúa funcionando como la organización administrativa ordinaria, si bien bajo las directrices del Gobierno central que a tal efecto podrá:

- dictar las disposiciones y órdenes necesarias

- establecer un régimen de comunicación o autorización previa.

- acordar nombramientos, ceses y sustituciones.

- exigir responsabilidades disciplinarias.

C) Medidas singulares sobre determinados ámbitos de la actividad administrativa.

- C.1 Seguridad y orden públicos: Despliegue de las Fuerzas y Cuerpos de seguridad del Estado en coordinación con los Mossos d'Esquadra que asimismo podrán ser sustituidos.

- C.2 Área de gestión económica, financiera, tributaria y presupuestaria: Garantizar que los fondos transferidos y los ingresos recibidos no se destinen al proceso secesionista.

- C.3 Área de telecomunicaciones y comunicaciones electrónicas y audiovisuales: Estas áreas se atribuyen al Gobierno central, si bien en el debate parlamentario se acordó excluir el ámbito del servicio público de comunicación audiovisual que incluye la radio y la televisión públicas catalanas.

D) Medidas dirigidas al Parlament de Cataluña.

- D.1 Prohibición de que la Presidencia del Parlament proponga candidato a la Presidencia de la Generalitat o celebre debate de investidura.

- D.2 Inaplicabilidad de las funciones de control e impulso parlamentario del Gobierno previstas en el Reglamento del Parlament. Atribución de las funciones de control a la Comisión conjunta General de las Comunidades Autónomas y Constitucional. 
- D.3 Sujeción de las propuestas de resolución al Acuerdo del Senado, si bien en el debate parlamentario se acordó excluir el requisito de la previa conformidad del Gobierno.

- D.4 Sujeción de las iniciativas legislativas al Acuerdo del Senado, si bien en el debate parlamentario se acordó excluir el requisito de la previa conformidad del Gobierno.

\section{E) Medidas de carácter transversal.}

- E.1 Sujeción de la normativa estatal y autonómica de aplicación a la jurisdicción contencioso-administrativa.

— E.2 Nulidad de pleno derecho de disposiciones, actos y resoluciones autonómicos que contravengan el Acuerdo del Senado.

- E.3 Publicación en los boletines oficiales de la Generalitat.

- E.4 Atribución al Gobierno de las facultades de modificación y organización de la Administración.

- E.5 Habilitación al Gobierno para la creación de órganos y el nombramiento de autoridades.

- E.6 Habilitación al Gobierno para dictar disposiciones y protocolos de actuación.

- E.7 Nulidad de pleno derecho de los expedientes sancionadores que la Administración de la Generalitat hubiese incoado a funcionarios o empleados por considerar infracción los presupuestos que motivan el Acuerdo del Senado.

- E.8 Atribución al Gobierno de la potestad disciplinaria de las infracciones de las medidas acordadas por el Senado que se entenderán como incumplimientos del deber de fidelidad a la Constitución y al Estatuto con el consiguiente traslado al Ministerio Fiscal si procediese.

- E.9 Duración de las medidas hasta la toma de posesión del nuevo Gobierno autonómico que resulte de las elecciones al Parlament y posibilidad de su revisión si cesasen las causas que las motivaron. En el debate parlamentario del Senado se introdujo el compromiso del Gobierno a una utilización proporcionada y responsable de las medidas acordadas.

- E.10 Notificación a los miembros del Gobierno de la Generalitat y a la Mesa del Parlament.

Paralelamente se incluyen algunos Reales Decretos de ejecución del Acuerdo, todas con la misma fecha del 27 de octubre de 2017:

RD 942/2017 de cese del Presidente de la Generalitat.

RD 943/2017 de cese del Vicepresidente y Consejeros del Gobierno de la Generalitat. 
RD 944/2017 de designación del Presidente, Vicepresidenta y Ministros del Gobierno del Estado como órganos habilitados para la aplicación del Acuerdo del Senado, con determinación de las funciones correspondientes a cada uno.

RD 945/2017 de supresión de diversos órganos administrativos: Oficina del Presidente, Oficina del Vicepresidente, Consejo Asesor para la Transición Nacional, Comisión espacial sobre la violación de derechos fundamentales en Cataluña, DIPLOCAT)

RD 946/2017 de disolución del Parlamento de Cataluña y convocatoria de elecciones.

Otras normas reglamentarias fueron dictadas en fechas posteriores: RD 954/2017 de cese de distintos altos cargos de la Generalitat. RD 983/2017 de nombramiento de Directora General de Modernización de la Administración de Justicia de la Generalitat.

RD 990/2017 de nombramiento de Director General de Centros Concertados y Privados de la Generalitat.

OM INT/1038/2017 de cese de D. Josep Lluis Trapero en la plaza de Mayor de la Escuela Superior de Mossos d'Esquadra.

OM ECD/1142/2017 de nombramiento de Presidente del Consejo de Dirección del Consosrcio de Educación de Barcelona.

OM INT 1074/2017 de delegación de funciones en órganos del Departamento de Interior de la Generalitat.

O PRE/255/2017 de delegación de competencias en el titular de la Secretaría General de Presidencia.

Constituyen precedentes de la iniciativa del Consejo de Ministros, algunos acuerdos de la Comisión Delegada de Asuntos Económicos que establecían medidas de control de las cuentas de la Generalitat ${ }^{7}$.

La decisión del Consejo de Ministros de promover la coerción estatal del art. 155 fue objeto de sendos recursos de amparo ante el Tribunal Constitucional que fueron inadmitidos a trámite en otras tantas resoluciones del 26 de octubre de 2017. El primero, interpuesto por el abogado Oriol Casals fue inadmitido por su carácter prematuro en tanto que las medidas propuestas por el Gobierno no habían sido aún aprobadas por el Senado y, por consiguiente, eran susceptibles de modificación o rechazo. Más breve fue la fundamentación de la resolución del Tribunal para inadmitir el instado por los senadores del PdCAT en la que se limitó a advertir la «manifiesta inexistencia de un derecho fundamental tutelable en amparo». También

7 Orden PRE/2454/2015 de condiciones impuestas a la Generalitat para acceder al Fondo de Financiación a las Comunidades Autónomas. Órdenes PRA/686/2017, HFP/878/2017, HFP/996/2017 sobre pagos a acreedores por cuenta de la Comunidad Autónoma de Cataluña. Orden HFP/886/2017 por la que se declara la indisponibilidad de créditos en el Presupuesto de la Comunidad Autónoma de Cataluña para 2017. OM HFP/1102/2017 sobre el cierre contable del ejercicio presupuestario 2017. 
en la misma fecha, la Sala de lo contencioso administrativo del Tribunal Supremo denegó la petición cautelarísima planteada por la Generalitat de Catalunya y el Govern de suspender el acuerdo del Consejo de Ministros, al considerar que se trata del

«acto de iniciación de un procedimiento constitucional, el del artículo 155 de la Norma Fundamental, que se dirige al Senado y que en el momento actual sólo se ha iniciado y no produce por ello los efectos jurídicos "ad extra" que sostiene la parte recurrente».

Con un argumento semejante, el Tribunal Constitucional dictó el Auto 142/2017 de 31 de octubre para inadmitir el recurso de inconstitucionalidad instado por el Gobierno de la Generalitat por cuanto que se instó con anterioridad a que el acuerdo fuese aprobado por el Senado y publicado en el B.O.E. Finalmente el Tribunal Constitucional se pronunciará a resultas de los recursos de inconstitucionalidad instados por el Grupo Parlamentario de Unidos-Podemos en diciembre de 2017 y, algo después, por el Parlament de Cataluña.

Por su parte, el Grupo parlamentario del P.S.C. instó sendos recursos de amparo contra la celebración del Pleno convocado por la Mesa al objeto de valorar los resultados del referéndum del 1 de octubre de 2017 y sus efectos y que fue admitido mediante ATC 137/2017; y frente al Acuerdo de la Mesa del Parlament de 27 de octubre por la admisión a trámite de la propuesta de resolución presentada por los grupos de Junts pel Sí y la C.U.P. sobre el proceso constituyente que también fue admitido mediante Providencia de 27 de octubre de 2017. Ello no obstante, el 26 de octubre de 2017 se celebró el Pleno del Parlament de Cataluña y se votó la proclamación de la República catalana ${ }^{8}$.

${ }^{8}$ Esta proclamación fue más tarde suspendida por Providencia del Tribunal Constitucional de 31 de octubre de 2017, a resultas del incidente ex arts. 87 y 92 L.O.T.C. de ejecución de la STC 114/2017 de17 de octubre, que declaró la inconstitucionalidad y nulidad de la Ley del Parlamento de Cataluña 19/2017, de 6 de septiembre, denominada «del referéndum de autodeterminación; así como de la Providencia de 12 de septiembre de 2017, que admite a trámite el recurso de inconstitucionalidad núm. 4386-2017, contra la Ley del Parlamento de Cataluña 20/2017, de 6 de septiembre, denominada «de transitoriedad jurídica y fundacional de la república». El Tribunal Constitucional declaró la inconstitucionalidad de la Ley 19/2017 y de la Ley 20/2017 en otras tantas Sentencias del 24 de octubre y del 8 de noviembre de 2017.

Los mismos argumentos de la STC 114/2017 fundamentaron las tres sentencias que el Tribunal Constitucional dictó el 31 de octubre de 2017 para estimar otras tantas impugnaciones del Gobierno ex arts. 161.2 C.E y 76, 77 L.O.T.C. y declarar la inconstitucionalidad y nulidad del Decreto de la Generalitat de Cataluña 140/2017, de 7 de septiembre, de normas complementarias para la celebración del referéndum de autodeterminación; del Decreto de la Generalitat 139/2017, de 6 de septiembre, de convocatoria del referéndum de autodeterminación y de la Resolución 807/XI del Parlamento de Cataluña por la que se designan los miembros de la sindicatura electoral de Cataluña.

El Auto 144/2017 de 8 de noviembre estimó el incidente de ejecución de la STC 114/2017 instado por el Gobierno y declaró la inconstitucionalidad de las Resoluciones del Parlament de Cataluña de 27 de octubre de 2017 denominadas «Declaración de los representantes de Cataluña» y «Proceso constituyente» 
Tras recibir la propuesta del Gobierno, la Mesa del Senado dio trámite de alegaciones al Presidente de la Generalitat que fueron publicadas en el B.O.C.G. n. ${ }^{\circ} 165$ del 27 de octubre ${ }^{9}$. Carles Puigdemont reitera el contenido de sus contestaciones al requerimiento del Gobierno y recoge la «tesis Arbós» de la interpretación conexa de los apartados 1 y 2 del art. 155 de forma que las medidas que el Gobierno puede «adoptar» según el art. 155.1 solo se podrían «ejecutar» mediante el mecanismo que establece el art. 155.2, es decir dando instrucciones a las autoridades de las Comunidades Autónomas con pleno cumplimiento del Estatuto de Autonomía y de los arts.2, 136, 137 y 155 de la Constitución que obligan a respetar la organización institucional de la Generalitat.

Resulta curioso resaltar que el Presidente Puigdemont invocase el debate constituyente del art. 155 para recordar el rechazo mayoritario al voto particular que Manuel Fraga Iribarne (también a dos enmiendas del diputado José M. Ortí Bordás y del senador Alberto Ballarín Marcial, ambos de la U.C.D.) defendió en la Cámara propugnando la introducción de sendos apartados que previesen la suspensión de los órganos autonómicos y el nombramiento de un Gobernador general. Al invocar este episodio del debate constituyente, Carles Puigdemont claramente pretendía denunciar la aparente contradicción del Gobierno de Mariano Rajoy con los parlamentarios constituyentes de 1978.

Tras recibir estas alegaciones del Presidente de la Generalitat y en sesión del mismo día 27 de octubre de 2017, el Senado aprobó las medidas propuestas por el Gobierno con algunas enmiendas especialmente en materia del control a los medios de comunicación pública (apartado C.3), control por una autoridad gubernativa de la constitucionalidad de los actos del Parlamento (apartado D.4) y temporalidad de las medidas (apartado E.9). La Resolución fue publicada en el B.O.E. del mismo viernes. En su posterior comunicación pública, el Presidente del Gobierno anunció la convocatoria de elecciones autonómicas para el 21 de diciembre de 2017.

Tal y como resulta de una enmienda presentada por los senadores canarios, las facultades del Gobierno central no habrían de alcanzar a poder vetar cualesquiera decisiones que adopte el Parlament incluso antes de nombrar Govern (apartado D.4). El Acuerdo del Senado fija expresamente que las medidas del art. 155 cesan con la formación de un nuevo Govern autonómico, si bien entre la constitución del Parlament y la investidura del President y su gobierno puede transcurrir un tiempo ilimitado. Corresponde al Presidente del Parlament proponer candidato para su investidura parlamentaria. El plazo de los dos meses para la disolución de la cámara si ningún candidato hubiese sido investido, solo empieza a correr a partir de la primera votación art (67.3 del Estatut).

Esta última cuestión no es baladí. Cuando, como en el caso de las elecciones al Parlament del 21 de diciembre de 2017, el espectro parlamentario está muy fragmentado, los pactos políticos devienen necesarios tanto para elegir la Mesa como

${ }^{9}$ http://cadenaser00.epimg.net/descargables/2017/10/26/7b8a952d0b10c4068ffb6fed062a579c.pdf 
para investir Presidente. La elección de la Presidencia del Parlament resulta decisiva porque le compete nombrar candidato a Presidente de la Generalitat, de modo que la primera votación de su investidura constituye la fecha a quo de los dos meses que prevé el art. 4.6 de la Ley 13/2008 para que en el caso de que ningún candidato fuese investido, disolver la Legislatura y convocar nuevas elecciones. El art. 44 del Reglamento del Parlament regula la elección del Presidente de la cámara con la particularidad de que prevé hasta seis votaciones: En la primera, el candidato precisa mayoría absoluta; en la segunda, se lleva a cabo un ballottage entre los dos diputados más votados; y las cuatro restantes están previstas para desempatar una eventual paridad o, en su defecto, es elegido el candidato del grupo parlamentario con más diputados.

Por otra parte y a la fecha de constitución del Parlament, Carles Puigdemont y otros cuatro diputados electos, Lluis Puig, Antoni Comín, Clara Ponsatí, Meritxell Serret, permanecían en Bélgica, sujetos a una orden de búsqueda y captura, tras que el Juez Llanera decidiese retirar la orden europea de detención ${ }^{10}$. Y otros cuatro en prisión provisional, concretamente Oriol Junqueras, Joaquim Forn, Jordi Sánchez y Jordi Cuixart. Éstas D. P. n. ${ }^{\circ} 82 / 2017$ de la Audiencia Nacional, además de las querellas instadas ante el Tribunal Supremo frente a Carme Forcadell y otros miembros de la Mesa, se acumularon en la Causa especial T. S. n. ${ }^{\circ}$ 20907/2017 según decretó su Sala Segunda mediante Auto de 24 de noviembre de 2017.

Esta situación no impediría que los parlamentarios electos, fugados o reclusos pudiesen obtener su acta de diputados porque el art. 23.1 del Reglamento exige tan solo dos requisitos: presentar la credencial para jurar/prometer el cargo; y presentar declaración de actividades y bienes. Cuestión distinta sería que, sin comparecer en el Parlament, Carlos Puigdemont u otro cualquiera de ellos pudiese postularse como candidato a la Presidencia de la Generalitat. El art. 4 de la Ley 13/2008 del President de la Generalitat regula los trámites del procedimiento de elección del Presidente de la Generalitat y en particular la presentación ante el Pleno de su programa de investidura. Sucede que esta Ley del President de la Generalitat está incluida entre las materias que el art. 62 del Estatut enumera como reservadas a las denominadas leyes de desarrollo básico del Estatuto. La modificación de cualquiera de estas leyes precisa de

10 Auto de 5 de diciembre de 2017: Por otro lado, los hechos investigados suscitan la eventual comisión de un delito de naturaleza plurisubjetiva. $Y$, también con posterioridad a que se emitieran las órdenes de detención que contemplamos, se ha definido que los hechos pudieran haberse perpetrado mediante el concierto de todos los investigados y con una unidad jurídica inseparable, esto es, que la depuración de las distintas responsabilidades penales debe ser llevada de manera unificada (...). De este modo, el actual mantenimiento de las órdenes de detención, lejos de facilitar un adecuado desarrollo del proceso, puede introducir una restricción de efectos sustanciales, pues al ser posible que el Estado requerido (en aplicación de los artículos 3 a 5 de la Decisión Marco), deniegue parcialmente la ejecución de las órdenes de detención, se está posibilitando una restricción del título de imputación para los investigados que se encuentran fugados, lo que — de acontecer — dificultaria la respuesta bomogénea que justificó la acumulación de las actuaciones ante este Tribunal, introduciendo una distorsión sustantiva a las defensas de los encausados que sí están a disposición de este órgano instructor, quienes podrían ser investigados y enjuiciados por todos los delitos que el instructor contempla, colocándose así en «peor derecho» que quienes se encuentran fugados. 
la mayoría absoluta del Parlament. Ciertamente que una mayoría absoluta de los parlamentarios favorables a las tesis independentistas de Carles Puigdemont podría modificar este precepto y regular la investidura de un Presidente ausente. Otra posibilidad sería la de reformar también por mayoría absoluta (art. 58.3 del Estatut) tan solo el art. 146 del Reglamento del Parlament, sobre el debate de investidura, para introducir que el candidato a President pueda presentar su programa de gobierno al Pleno por vía telemática. Claro está que cualquiera de estas alternativas constituiría una anomalía inusitada en la historia del parlamentarismo europeo susceptible de recurso de inconstitucionalidad.

La otra enmienda sobre el control a los medios de comunicación mereció un muy interesante artículo del prof. Ruiz Robledo ${ }^{11}$. Critica que las medidas ex art. 155 aprobadas por el Senado no fuesen publicadas en el B.O.E. con un texto consolidado, sino que, antes al contrario, se publicasen separadamente la solicitud del Gobierno y la autorización del Senado. De este modo, no consta consolidada la enmienda aprobada al Grupo parlamentario socialista sobre el control de los medios catalanes de comunicación pública, conforme a la cual se suprimió el párrafo C.3.3, es decir el control del servicio público autonómico de comunicación audiovisual para garantizar una información veraz y objetiva. Sostiene el prof. Ruiz que, ello no obstante, el apartado B del Acuerdo que faculta al Gobierno central para el control de cualesquiera organismos, entes, entidades y empresas públicas vinculadas o dependientes de la Administración de la Generalitat, permitiría la intervención de la Corporación catalana de Medios Audiovisuales y de la empresa Televisió de Catalunya para evitar así que la televisión catalana siga al servicio del independentismo más recalcitrante.

La opinión de Agustín Ruiz Robledo responde a una interpretación objetiva de la norma difícilmente rebatible con argumentos jurídicos. Ahora bien, esta enmienda formó parte del pacto entre el Partido Popular y el Partido Socialista con el que se aprobó el Acuerdo del Senado. Tratándose de una propuesta del Grupo parlamentario socialista, no parece imaginable que el Gobierno central invocase en algún momento el apartado B para intervenir TV3. Más aún, tampoco parece aconsejable para los intereses ni del P.P. ni del P.S.O.E. objetar un pacto de Estado tan laborioso de alcanzar y tan frágil de sostener.

\section{LA APLICACIÓN DE LA COERCIÓN ESTATAL DEL ART. 155 EN CATALUÑA. LA POLARIZACIÓN DEL ELECTORADO}

Creo que soy objetivo si afirmo que la decisión de declarar la coerción estatal del art. 155 no fue de buen grado ni para el Gobierno central ni para la Generalitat.

${ }^{11}$ Agustín RUIZ ROBLEDO: «El control de TV3» en el diario madrileño El País, edición del 7 de diciembre de 2017. 
Probablemente ambos temían un escenario mucho más conflictivo que el que se ha dado. No se convocaron protestas públicas masivas. La Universidad siguió sus actividades con notable normalidad. La huelga convocada por la Intersindical CSC desde el 30 de octubre al 9 de noviembre tuvo escaso eco además de la oposición de otras centrales sindicales, de modo que fue finalmente desconvocada. Desde que se declaró la coerción estatal del art. 155, la vida cotidiana de la ciudadanía catalana transcurrió con aparente normalidad.

El Gobierno central envió a Barcelona al Secretario de Estado para Administraciones Territoriales, Roberto Bermúdez de Castro, al mando de apenas media docena de funcionarios. Los empleados públicos de la Generalitat continuaron ejercitando sus funciones en su lengua, con profesionalidad, sin sorpresas ni instrucciones especiales. Tan solo fueron cesados aquellos altos cargos directamente implicados en el procés independentista encausado por el Tribunal Supremo. A resultas de la enmienda del Partido Socialista en el Senado, no se intervinieron los medios de comunicación públicos. Tampoco se alteró el modelo de inmersión lingüístico en la educación. En el mando de los Mossos d'Esquadra, se sustituyó el mayor Josep Lluis Trapero, asimismo encausado en las D. P. 82/2017, por su segundo Ferran López.

Cuestión distinta es la de las percepciones de la intervención del Gobierno central en la opinión secesionista y en los sectores constitucionalistas. En los primeros cundió una intolerable sensación de represión política. Y en los segundos, una dolorosa interpretación de tibieza en las medidas adoptadas.

La decisión de tan rápida convocatoria electoral para el 21 de diciembre de 2017, apenas diez semanas después de la declaración del art. 155, relajó las actitudes más combativas. Tras unos iniciales titubeos de las C.U.P., también los partidos independentistas confirmaron su participación. Lejos del proyecto soberanista de unas elecciones constituyentes de la República catalana, los comicios de diciembre de 2017 fueron indiscutiblemente autonómicos.

La aplicación de la coerción estatal del art. 155 mereció la comparecencia a petición propia de la Vicepresidenta Saénz de Santamaría ante la Comisión General de las Comunidades Autónomas y Constitucional del Senado el 18 de diciembre de 2017. Su discurso se estructuró en dos ideas centrales: En primer lugar, la aplicación con rigor, responsabilidad y respeto del art. 155 conforme a lo previsto: la liquidación de las estructuras de Estado ilegales (Diplocat, la Hacienda catalana), el pago a proveedores, la convocatoria de elecciones autonómicas. Y, en segundo lugar, la denuncia de deslealtad a los líderes de un procés imposible e inviable, un fake basado en la posverdad en la que las falsedades no solo viajaban por la red, sino también en coche oficial. Las principales críticas a su intervención provinieron de los portavoces de E.R.C y del PdeCAT. Miquel A. Estradé acusó al Gobierno de ignorar la separación de poderes y Josep L. Cleries de prácticas franquistas que habrían devastado a Cataluña.

Finalmente los resultados del 21 de diciembre no variaron sustancialmente el espectro del Parlamento catalán. Los tres partidos independentistas (Junts per Cata- 
lunya con 34, E.R.C. con 32 y C.U.P. con 4) revalidaron la mayoría absoluta de sus escaños hasta sumar 70 aunque sus votos no llegasen al $50 \%$. Esta realidad deslució la victoria electoral de los 36 escaños de Ciudadanos, un partido de inequívoco perfil constitucionalista. Una vez más, la encuesta que el C.I.S. publicó el 4 de diciembre no acertó ni al predecir que los partidos independentistas quedarían por debajo de la mayoría ni en vaticinar la victoria electoral de E.R.C.

Las disensiones que han dejado tanto la declaración unilateral de independencia del Parlament de Cataluña como la aplicación de la coerción estatal del art. 155 son muy profundas. La sociedad catalana está radicalmente dividida por esta cuestión y no parece capaz de consensuar proyectos integradores.

\section{LA CUESTIÓN PROCESAL DE LA RECURRIBILIDAD DEL ACUERDO DEL SENADO}

Tanto previamente el Consell de Garanties Estatutàries como después, al interponer sus recursos de inconstitucionalidad, el Parlamento de Cataluña y los diputados de UNIDOS-PODEMOS han suscitado el problema procesal de determinar si, por tratarse de un real decreto, el Acuerdo del Senado es susceptible de recurso de inconstitucionalidad.

A mi entender, aunque no se trate de una ley formal, basta con invocar el art. 27 de la L.O.T.C. ( «disposiciones normativas y actos del Estado con fuerza de ley») para sostener la recurribilidad del Acuerdo ante el Tribunal Constitucional. De hecho, el Acuerdo del Senado fija cuál es el marco jurídico de la intervención del Gobierno central y enumera las medidas cuyo objeto es precisamente el de alterar temporalmente normas constitucionales y legales vigentes, particularmente el cuadro de distribución de competencias entre el Estado y la Comunidad Autónoma. De este modo, el Acuerdo da cobertura legal y autoriza al Gobierno central a desarrollar actuaciones que de otra manera resultarían contrarias al Ordenamiento Jurídico, al bloque de constitucionalidad y al principio de autonomía del art. 2 de la Constitución.

No parece que esta cuestión debiera generar mayor objeción. El ATC 7/2012 (reiterado como precedente de la STC 83/2016) sostuvo la condición de disposición con fuerza de ley de la declaración del estado de alarma del 4 de diciembre del 2010. Como aquella declaración, tampoco este Acuerdo del Senado tiene rango formal de ley. Ahora bien, ambas son disposiciones normativas con fuerza de ley porque en ambos casos interviene un órgano parlamentario: El Congreso para la declaración y prórroga del estado de alarma; y el Senado para la declaración de la coerción estatal del art. 155. Y porque en ambos casos se afecta a normas legales para excepcionarlas, suspenderlas o modificar su aplicabilidad de forma legítima:

Si la Constitución y el ordenamiento habilitan a determinados actos, decisiones o resoluciones parlamentarias para modificar de tal modo la aplicación de las leyes, no es de dudar que tales actos, decisiones o resoluciones ostenten ese genérico rango o valor de ley. 
La consecuencia necesaria es que la vía adecuada para su impugnación es la del recurso de inconstitucionalidad:

«Si la Constitución y el ordenamiento habilitan a determinados actos, decisiones o resoluciones parlamentarias para modificar de tal modo la aplicación de las leyes, no es de dudar que tales actos, decisiones o resoluciones ostenten ese genérico «rango» o "valor» de ley que invoca para acotar su objeto el art. 42 LOTC, con la consecuencia de que los mismos son insusceptibles del recurso de amparo previsto en tal precepto y sólo cabe impugnarlos ante este Tribunal a través de los procesos constitucionales previstos en la Constitución y en la Ley Orgánica del Tribunal Constitucional que tienen por objeto el control de constitucionalidad de las leyes, normas y actos con fuerza o valor de ley», resolvió aquel mismo Auto.

Además de este precedente del ATC 7/2012 a propósito de la declaración del estado de alarma, el recurso de inconstitucionalidad instado por el Parlamento de Cataluña invoca ex abundantia la STC 42/2014 sobre la inconstitucionalidad de la Resolución del Parlamento de Cataluña 5/X por la que se aprueba la Declaración de soberanía y el derecho a decidir del pueblo de Cataluña. En aquella Sentencia, el Tribunal sostuvo que una declaración parlamentaria susceptible de producir futuros efectos jurídicos es impugnable en vía constitucional.

Sorprende, sin embargo, que los recurrentes, tanto UNIDOS-PODEMOS como el Parlament de Cataluña, hayan incurrido en la contradicción de sostener que el real decreto con que se aprobó el Acuerdo es una norma con fuerza de ley para ser recurrida pero no tiene fuerza de ley para suspender el Estatuto de Autonomía so pena de infringir el principio de jerarquía normativa. El art. 155 de la coerción estatal es un procedimiento constitucional extraordinario que no está sujeto a ninguna especial limitación más allá de la finalidad de restablecer el orden constitucional o el interés general vulnerados. Resultaría de todo punto absurdo que, atendidas tan graves finalidades, el real decreto del Gobierno no tuviese fuerza de ley sino un menor rango reglamentario.

Tampoco la legitimación activa del Parlamento de Cataluña para instar el recurso de inconstitucionalidad debiera, a mi entender, generar objeción alguna. El art. 162.1.a C.E. legitima a los órganos ejecutivos y legislativos de las Comunidades Autónomas y el art. 32.2 L.O.T.C. constriñe esta legitimación a que la ley o disposición con fuerza de ley afecte al ámbito de autonomía del recurrente. La STC 199/1987 delimitó esta legitimación y la extendió a todos aquellos supuestos en que exista un punto de conexión material entre la ley estatal y el ámbito competencial autonómico. Pues bien, es muy obvio que el Acuerdo del Senado recurrido afecta a la Generalitat de Cataluña y, en consecuencia, es de prever que el Tribunal confirme su legitimación activa para instar el recurso.

La cuestión más concreta de que la legitimación del Parlamento de Cataluña (disuelto por aplicación del Acuerdo del Senado ex art. 155) sea ejercitada por su Diputación Permanente, responde al precedente pro actione del ATC 547/1989. El art. 2.2 E.A.C. establece que corresponde a la Diputación Permanente el ejercicio de las facultades del Parlamento durante sus períodos de inactividad; y, entre ellas, 
según el art. 74.2.f R.P.C., ejercer las facultades parlamentarias en materia de constitucionalidad y conflictos de competencia. Así pues, por estar disuelto, el Parlamento no puede ejercer la propia facultad de acordar la interposición de recursos de inconstitucionalidad tal y como le atribuye el art. 174.1 R.P.C.; y, en consecuencia, esta facultad se transfiere a la Diputación Permanente, hasta tanto se levante la aplicación del art. 155 con motivo de la toma de posesión del nuevo Govern que sea elegido por el Parlament electo.

Otro problema procesal añadido es el de la personación del Consejo de Gobierno de la Generalitat. Los recurrentes han denunciado la indefensión que supone que el Gobierno de la Generalitat esté intervenido y que, por consiguiente, no pueda comparecer en los Autos. La Providencia del 13 de noviembre de 2017 (JUR 2017/309430) ha sido la primera de otras tantas que han resuelto el problema. El Tribunal ha acordado la suspensión del plazo para formular alegaciones en tanto el Consejo de Ministros ejerza las funciones y competencias que corresponden al Consejo de Gobierno de la Generalitat de Catalunya ${ }^{12}$. Posteriormente, este mismo criterio es el que se mantuvo en la Providencia de 10 de enero de $2017^{13}$ por la que se admitió a trámite del recurso de inconstitucionalidad de UNIDOS-PODEMOS.

\section{EL RECURSO DE INCONSTITUCIONALIDAD DE UNIDOS-PODEMOS}

A petición especialmente de E.R.C., 50 diputados del Grupo Parlamentario de Unidos-Podemos instaron un recurso de inconstitucionalidad frente a la totalidad de la Resolución del Senado de 27 de octubre de 2017 o, subsidiariamente frente a sus apartados A, B, C1, D, E2 y E3. Sus firmantes no ocultaron que la autoría intelectual del texto se debe al prof. Joan Vintró de la Universitat de Barcelona. De hecho, su lectura constata que el estilo del escrito no es propiamente forense.

Sobre la cuestión procesal del recurso, invoca el art. 27 de la L.O.T.C. («disposiciones normativas y actos del Estado con fuerza de ley») para sostener que, aunque no tenga rango formal de ley, el Acuerdo es susceptible de recurso de inconstitucionalidad.

Los argumentos materiales del recurso afectan a la «especial extensión e intensidad en las posibilidades de alteración del marco ordinario de actuación del Estado y la Comunidad»; y se centran en dos:

A) Vulneración del procedimiento del art. 155 de la Constitución porque el Acuerdo ignoraría las alegaciones del Presidente de la Generalitat y no

${ }^{12}$ Con el fin de evitar un conflicto en la defensa de los intereses del Estado y de la Comunidad Autónoma de Cataluña, se suspende el plazo para que el Gobierno de Cataluña pueda personarse y formular alegaciones, en tanto el Consejo de Ministros, de conformidad con el art. 5 del Real Decreto 944/2017, de 27 de octubre, ejerza las funciones y competencias que corresponden al Consejo de Gobierno de la Generalitat de Catalunya.

${ }^{13}$ N. ${ }^{\circ}$ de asunto $5884 / 2017$. 
acreditaría el incumplimiento grave y lesivo que el requerimiento cursado imputa a la Comunidad Autónoma; porque el Acuerdo no respetaría la obligada coherencia con el contenido del requerimiento previo ni definiría las concretas actuaciones irregulares de la Generalitat que habrían constituido o un incumplimiento de obligaciones constitucionales o un atentado al interés general; y porque el Acuerdo del Senado introduciría unas actuaciones que no habrían sido previamente determinadas en el requerimiento.

Para los recurrentes, tanto el preceptivo requerimiento del Gobierno central como el posterior Acuerdo del Senado concretan el incumplimiento denunciado en un único particular: la confirmación de que la Generalitat habría declarado unilateralmente la independencia y anunciado un posterior proceso constituyente. Esta declaración unilateral es el objeto del requerimiento, así como su revocación es la finalidad del mismo. Sucede que en sus dos contestaciones del 16 y del 19 de octubre, el Presidente de la Generalitat reiteró la suspensión de la declaración unilateral de independencia y, por consiguiente, no habría lugar a cumplimentar ni el objeto del requerimiento ni la finalidad del mismo. No puede considerarse rechazado un requerimiento que se basa en un incumplimiento que las instituciones autonómicas niegan haber realizado. Por otra parte, el Presidente Puigdemont habría ofrecido la medida alternativa y preventiva del diálogo político entre los dos gobiernos. En el mismo sentido, denuncian la negativa del Senado a aceptar la intervención en el Pleno de Ferran Mascarell, Delegado de la Generalitat en Madrid, ex art. 189.3 R.S. (designación de representante a los efectos de remitir antecedentes, datos y alegaciones). La conclusión de los recurrentes sería que se habrían vulnerado el R.S. art. 189.1 que exige del Gobierno que justifique el incumplimiento grave y lesivo por la Comunidad Autónoma del requerimiento cursado, y art. 189.3 por la resolución de la Mesa de la Comisión al rechazar la intervención de D. Ferran Mascarell.

Tampoco consideran los recurrentes que el Acuerdo del Senado guarde la exigible coherencia con el requerimiento previo. Mientras que el requerimiento se constreñía a una eventual declaración de independencia, el Acuerdo del Senado imputa además un atentado al interés general y en su apartado «D» enumera objetivos más amplios y complejos que se refieren a cuestiones tales como el deterioro del bienestar social y económico o a la fractura de la convivencia. Estas circunstancias determinarían la inconstitucionalidad del Acuerdo porque no respetaría la obligada coherencia con el requerimiento; y porque tampoco definiría las actuaciones concretas de la Generalitat que constituirían un incumplimiento de obligaciones constitucionales o atentarían al interés general.

Y por último, los recurrentes sostienen el carácter integrado de los actos del procedimiento del art. 155 y acusan al Gobierno y al Senado de indeterminación e 
incoherencia en la determinación de las medidas del art. 155. Sus argumentos se centran en que el Acuerdo del Senado introduce unas actuaciones que no habían sido determinadas en el requerimiento previo: cese del Gobierno de la Generalitat, intervención de la Administración autonómica, disolución del Parlamento de Cataluña. De este modo, el Senado se ve privado de los argumentos que el Presidente de la Generalitat habría podido alegar para contradecir las medidas que no se concretaron en el requerimiento.

B) Vulneración del alcance del art. 155 y su interpretación sistemática y proporcional con los demás preceptos de la Constitución porque el Acuerdo afecta a instituciones que, como el Parlamento de Cataluña, no pueden ser objeto de la coerción estatal en cuanto que las somete a un régimen jurídico incompatible con el principio constitucional de la autonomía.

El recurso glosa la «tesis Arbós» de la interpretación conexa de los apartados 1 y 2 del art. 155 de forma que las medidas que el Gobierno puede «adoptar» según el art. 155.1 solo se podrían «ejecutar» mediante el mecanismo que establece el art. 155.2, es decir dando instrucciones (de hacer o de no hacer, vinculantes pero no a futuro) a las autoridades de las Comunidades Autónomas con pleno cumplimiento del Estatuto de Autonomía y de los arts. 2 y 137 de la Constitución que obligan a respetar la organización institucional de la Generalitat. Esta interpretación sería la más respetuosa con el carácter excepcional de la coerción estatal pues limita la ruptura del modelo constitucional ordinario al mínimo necesario para su restauración. De este modo, permanecen inalterados los instrumentos de control ordinario de las actuaciones de la Comunidad Autónoma también para impeler al cumplimiento de aquellas instrucciones, es decir los controles que establecen el art. 161.2 C.E. (impugnación ante el Tribunal Constitucional de disposiciones y resoluciones autonómicas), el art. 161.1.c C.E. (conflictos de competencia entre el Estado y las Comunidades Autónomas) y los arts. 87 y 92 L.O.T.C. (incidentes de ejecución de sentencias constitucionales).

Esto supuesto, el recurso concluye con un Suplico principal para que el Tribunal declare la inconstitucionalidad de todo el Acuerdo del Senado porque habilita al Gobierno a adoptar medidas que no se limitan a la restauración del orden constitucional, sino que tienen alcance incluso a futuro. Subsidiariamente formula un Suplico alternativo de inconstitucionalidad de sus apartados A, B, C1, D, E2 y E3 sustentado en una interpretación restrictiva y proporcional del art. 155 como última ratio.

El fundamento de este petitum subsidiario admite que el art. 155 habilita al Estado para sustituir competencias ordinarias de una Comunidad Autónoma, si bien esta sustitución debe atenerse a ciertos límites: la sustitución implicaría un cambio de autoridad temporal, sin afectar a sus mecanismos de control. La finalidad de la sustitución se constriñe a la restauración del orden constitucional. El objeto de la sustitución se limita a las decisiones ejecutivas pero en ningún caso a actuaciones parlamentarias o gubernamentales de libre decisión. La sustitución debería contraerse al ejercicio de aquellas atribuciones cuya suspensión resultase imprescindible (STC 
185/2016 sobre el art. 92 LOTC). Bajo esta premisa, los recurrentes pasan a referirse a las medidas de intervención del Ejecutivo y el Legislativo de la Generalitat en el Acuerdo del 27 de octubre de 2017.

Sobre las medidas referidas al Ejecutivo de la Generalitat, los recurrentes impugnan el cese y sustitución del Presidente de la Generalitat y su Gobierno por ser contrarias a la Constitución, arts. 2, 23, 24, 147 y 152 y al Estatuto de Autonomía, arts. 67, 68 y 70. Defienden que constituye una doble vulneración de la autonomía y del régimen parlamentario. La sustitución del Presidente y su Gobierno quebraría el principio de representatividad que establece que estos nombramientos resulten de la decisión electoral de los ciudadanos de la Comunidad y la confianza del Parlamento, con derecho de permanecer en los cargos salvo por las causas especialmente tasadas en la Ley. Tampoco el Acuerdo justificaría una relación de causalidad adecuada y proporcional entre la implementación del 155 y la finalidad de impedir la declaración unilateral de independencia y un posterior proceso constituyente, tanto más cuanto que son actuaciones que han sido anuladas o suspendidas. Más bien parecería una injustificable sanción a los miembros del Gobierno de la Generalitat con el objetivo principal del Acuerdo: la convocatoria anticipada de elecciones para de este modo conseguir el silenciamiento de la legítima representación ciudadana que resulta incómoda al Gobierno, y el intento de su sustitución como alternativa a enfrentar politicamente un conflicto. Por otra parte, estos ceses implicarían la pérdida del aforamiento (art. 70.2 E.A.C.) que comportaría una vulneración del derecho al juez ordinario predeterminado por la ley y, por ende, del derecho a la tutela judicial efectiva del art. 24 C.E.

El recurso demanda la inconstitucionalidad de otras tres medidas del Acuerdo. De un lado, el apartado B en el que se establece que entre las directrices que el Gobierno central puede dictar para la Administración de la Generalitat se incluye la de establecer un régimen de comunicación o autorización previa de sus actuaciones. En opinión de los recurrentes, este apartado altera las reglas de competencia entre el Estado y la Generalitat. De otro lado, en el apartado E del Acuerdo se prevé la nulidad de pleno derecho de disposiciones, actos y resoluciones autonómicos que contravengan el Acuerdo del Senado. Para los recurrentes el procedimiento del art. 155 no es propiamente legislativo y por consiguiente, el Acuerdo del Senado no puede implicar la nulidad de las actuaciones autonómicas que lo contradigan sustituyendo así la función que corresponde al art. 47 de la Ley 39/2015 de Procedimiento administrativo común so pena de vulnerar el principio de seguridad jurídica del art. 9.3 C.E. La tercera medida del apartado C que contempla la sustitución de los Mossos d'Esquadra por las Fuerzas y Cuerpos de seguridad del Estado supone, según los recurrentes, una vulneración ad casum de los arts. 37 a 39 y 45 a 50 de la Ley orgánica 2/1986 de Fuerzas y Cuerpos de Seguridad en los que se regularía el régimen de intervención de las policías autonómica y estatal.

Sobre las medidas referidas al poder Legislativo de la Generalitat, el recurso impugna, por ausencia de previsión constitucional expresa, la posibilidad del Presidente del Gobierno de acordar la disolución del Parlamento de Cataluña y convo- 
car elecciones autonómicas (apartado A). Así mismo, en su defecto, mientras continuase vigente la legislatura, el Acuerdo establece la prohibición de celebrar un debate de investidura y la inaplicabilidad de las funciones del control del Gobierno previstas en el Reglamento del Parlamento sobre las comisiones de investigación (arts. 66. y 67) y la limitación del contenido de las propuestas de resolución (apartado D). Argumentan los recurrentes que estas medidas vulnerarían el derecho a la participación electoral que regula la Constitución en sus arts. 23.1 y 23.2, además de la L.O.R.E.G. La atribución al Presidente del Gobierno central de la facultad de disolver el Parlamento de Cataluña y convocar elecciones autonómicas atentaría a la forma parlamentaria de gobierno de las Comunidades Autónomas (art. 152 C.E.). Añaden que la actividad parlamentaria no es sustituible; no puede tener más límites que los establecidos en la Constitución, el Estatuto y el Reglamento parlamentario; y tanto si es legislativa como si es deliberativa (STC 42/2014) está sujeta a control de constitucionalidad.

Los argumentos procesales del recurso parecen de menor enjundia que los materiales. Coincido con uno de los que ya manifestó el prof. Vernet en su voto particular al Dictamen del Consell de Garanties Estatutàries y que ahora reproducen los recurrentes: Habría resultado más respetuoso con los principios de gradualidad y temporalidad pero, sobre todo con la autonomía catalana que, en el requerimiento, el Presidente del Gobierno hubiese especificado que asumiría la facultad de disolver el Parlamento solo de manera subsidiaria para el supuesto de que no lo acordase el propio Presidente de la Generalitat. Sin embargo, en mi opinión, no será esta circunstancia motivo suficiente para declarar la inconstitucionalidad del procedimiento con que se declaró el art. 155. No existe incoherencia entre el requerimiento y el Acuerdo del Senado cuando éste se refiere a cuestiones tales como el deterioro del bienestar social y económico o a la factura de convivencia. El Acuerdo del Senado no las menciona como objetivos ex novo. Tal y como se argumenta en el apartado B, serían las consecuencias dimanantes del proceso soberanista de secesión que describe como una desobediencia rebelde sistemática y consciente de los reiterados pronunciamientos y requerimientos del Tribunal Constitucional, afectando de manera grave al interés general de España.

Ni el art. 155 de la Constitución ni el art 189 del Reglamento del Senado exigen que el requerimiento especifique las medidas que el Gobierno ha de someter a la aprobación del Senado. Son dos documentos diferentes con distintos destinatarios. Pero más allá de la literalidad de la norma, existe un argumento mucho más sólido: no parece responder a la ratio legis del precepto que el Presidente del Gobierno estuviese obligado a especificar las medidas antes de conocer la respuesta de la Comunidad Autónoma. El art. 155 regula un procedimiento que contrapone a un Presidente del Gobierno que cumple con sus obligaciones legales frente a una Comunidad Autónoma que incumple la Constitución de forma grave y contumaz. La finalidad de la coerción estatal es que la Comunidad Autónoma rectifique y esta es la perspectiva desde la que debe interpretarse el art. 155. La rectificación debe ser consecuencia de 
la simple denuncia del incumplimiento o del grave atentado al interés general y no de la amenaza del listado de medidas coercitivas. La coerción es la última ratio y no ha lugar a desvelarla hasta que la Comunidad Autónoma niegue la rectificación. No antes.

La activación de la coerción estatal del art. 155 es consecuencia de la reiterada desobediencia de las instituciones catalanas. Desoyendo todas las sentencias del Tribunal Constitucional, el Parlamento de Cataluña aprobó sendas leyes de convocatoria de un referéndum de autodeterminación y de proclamación de la República. El procés llegó a la Declaración unilateral de independencia y a ella se refiere el requerimiento del Presidente del Gobierno ( $S$ Si alguna autoridad de la Generalitat de Cataluña ba declarado la independencia...»). Los recurrentes se escudan en que aquellas leyes habrían sido declaradas inconstitucionales por el Tribunal Constitucional y en que el Presidente de la Generalitat habría contestado el requerimiento dando cuenta de la suspensión de los efectos del mandato popular resultante del referéndum de autodeterminación del 1 de octubre y ofreciendo a cambio un diálogo bilateral.

La apreciación por el Gobierno de que el incumplimiento denunciado fue grave responde a todas las Sentencias del Tribunal Constitucional desde la n. ${ }^{\circ}$ 259/2015. No parece que el Tribunal vaya a reconsiderar la gravedad del incumplimiento litigioso. Efectivamente el objeto y la finalidad del requerimiento es la declaración unilateral de independencia pero adviértase que el Presidente de la Generalitat respondió no ya reconociendo su revocación sino solo su suspensión. Esta sola circunstancia contradice la argumentación de los recurrentes cuando afirman que no puede considerarse rechazado un requerimiento que se basa en un incumplimiento que las instituciones autonómicas niegan haber realizado. Antes al contrario, me interesa destacar que solo cabe suspender aquello que ya se inició y si se inició, se realizó.

Tampoco la negativa del Senado a aceptar la intervención en el Pleno del Senado de Ferran Mascarell, Delegado de la Generalitat en Madrid, constituye un defecto procesal del art. 189. R.S. Este precepto establece que el Presidente de la Comunidad Autónoma puede designar un representante a los efectos de remitir a la Cámara cuantos antecedentes, datos y alegaciones considere pertinentes. La designación es una procura para presentar documentación pero no incluye la facultad de intervenir ante la Cámara. Conforme al art. 56.bis.2 R.S. el derecho de intervención en la sesión del Senado corresponde al Presidente o al miembro del correspondiente órgano colegiado del gobierno designado para ello. Y Ferran Mascarell no era miembro del Consejo de Gobierno de Cataluña.

Los argumentos materiales del recurso recogen las alegaciones del voto particular que Jaume Vernet y Margarida Gil formularon al Dictamen 14/2017 del Consell de Garanties Estatutàries. Reproducen la cuestión de si la discrecionalidad política con que el art. 155 faculta al Gobierno y al Senado, incluye la facultad de disolver al Parlamento y cesar al Gobierno autónomo o está limitada por el art. 152 de la Constitución, la L.O.R.E.G. y los Estatutos de Autonomía. 
Sobre la «tesis Arbós» que los recurrentes hacen suya, no creo que el apartado 2 del art. 155 constriña lo que se establece en el apartado 1. La facultad de dar instrucciones a las autoridades autonómicas no es la única sino una de las muchas posibles medidas necesarias para forzar al cumplimiento de las obligaciones constitucionales desobedecidas. Por otra parte, a mi entender, la facultad del Gobierno y del Senado para determinar las medidas necesarias tiene un amplio ámbito de discrecionalidad sujeto a la proporcionalidad del resultado constitucional pretendido.

En su petitum subsidiario, los recurrentes impugnan el cese del Presidente y su Gobierno porque en la aplicación del art. 155 no caben medidas que, como sucede con esos ceses, vulneran la Constitución y el Estatuto. Este argumento ya fue rechazado por el Tribunal Constitucional en la resolución del recurso de inconstitucionalidad instado por el Gobierno canario frente a la Ley orgánica 2/2012 de estabilidad presupuestaria y sostenibilidad financiera. En su Sentencia 215/2014 el Tribunal ya manifestó que el art. 155 supone una injerencia en la autonomía de las Comunidades Autónomas que lleva a una actuación subsidiaria del Estado, como reacción última a un incumplimiento flagrante de las obligaciones constitucionalmente impuestas.

Ha sido el propio Tribunal Constitucional quien viene insistiendo en el incumplimiento flagrante de la Constitución por parte de las autoridades de la Generalitat catalana. Al describir las vulneraciones de la Constitución, ha destacado su carácter de extrema gravedad. Conforme a esta doctrina, no parece que vaya a revocar por inconstitucional el cese del Gobierno de Cataluña. De hecho, en mi opinión, este argumento de los recurrentes incurre en mala fe procesal: no cabe invocar el cumplimiento de la Constitución (y su bloque de constitucionalidad) para argumentar en favor de incumplimientos de la Constitución precisamente para que se declaren constitucionales.

Más aún, no creo que quepa el argumento del bloque de constitucionalidad que invocan los recurrentes. No tendría sentido que con el pretexto de salvar el bloque de inconstitucionalidad, fuese la propia Constitución en su totalidad la que resultase fenecida en Cataluña. El art. 155 es un precepto de Derecho excepcional establecido para resolver problemas excepcionales. Su vocación es de temporalidad y su objeto afecta a situaciones en las que el ordenamiento constitucional está en serio peligro. No parece que el bloque de constitucionalidad deba de prevalecer sobre la Constitución misma.

El principio de representatividad y los derechos políticos del art. 23 no están por encima del principio de sujeción a la Constitución del art. 9.3. La condición de representantes de los ciudadanos no convierte a los políticos electos en sujetos inmunes a la ley. El art. 155 responde precisamente al supuesto de que se desobedezca la Constitución por parte de políticos representativos. Tampoco tendría sentido que con el pretexto de salvar el principio de representatividad de ciertos cargos políticos electos, fuese la propia Constitución en su totalidad la que resultase ineficaz en Cataluña.

Los recurrentes añaden otros tres petitums subsidiarios en relación a los apartados B, E y C del Acuerdo. El primero que impugna el régimen de comunicación 
previa a que se someten los actos de los funcionarios de la Generalitat consta poco fundamentado. Carecería de justificación que, una vez sustituidos los cargos cesados por miembros del Gobierno central, quedase sin efecto el principio de jerarquía del art. 103 de la Constitución. Conforme al apartado B del Acuerdo, la Administración de la Generalitat de Cataluña ha de continuar funcionando de manera ordinaria si bien bajo las directrices del Gobierno central. Por consiguiente, habremos de colegir que los funcionarios de la Generalitat responden a la jerarquía de sus superiores que pasan a ser los miembros del Gobierno central. La alteración de las reglas de competencia se produciría solo si se alterasen las funciones de la Administración de la Generalitat, es decir si se obstaculizase su ordinario funcionamiento.

El cese del Gobierno ha suscitado un problema procesal al que se refieren los recurrentes a propósito de la personación de la Generalitat en los recursos de inconstitucionalidad y demás procesos que se siguen en el Tribunal Constitucional. La Providencia del 13 de noviembre de 2017 (JUR 2017/309430) ya resolvió el problema de indefensión al acordar la suspensión del plazo de personación hasta que el Gobierno de la Generalitat recupere sus competencias ${ }^{14}$. Este mismo criterio es el que ha seguido la Providencia de 10 de enero de $2017^{15}$ en el recurso de inconstitucionalidad instado por UNIDOS-PODEMOS.

La impugnación del apartado $\mathrm{E}$ resulta contradictoria. Los recurrentes sostienen que se vulnera el principio de seguridad jurídica del art. 9.3 cuando se establece la nulidad de las disposiciones reglamentarias catalanas que contravengan el Acuerdo del Senado porque el procedimiento del art. 155 no es propiamente legislativo. La contradicción es flagrante: si, como sostienen los recurrentes al comienzo de su demanda, la declaración del art. 155 tiene fuerza de ley para poder ser objeto de su recurso de inconstitucionalidad, también tendrá fuerza de ley para sujetar los reglamentos al principio de legalidad.

$\mathrm{Y}$ en fin, no es cierto que los arts. 37 a 39 y 45 a 50 de la Ley orgánica 2/1986 de Fuerzas y Cuerpos de Seguridad del Estado regulen el régimen de intervención de las policías autonómicas. Los arts. 37 a 39 de esta Ley regulan las competencias de las policías; y los arts. 45 a 50 la colaboración policial, la adscripción de unidades de la policía nacional a las Comunidades Autónomas que así lo solicitasen, y los órganos de coordinación. El supuesto de hecho de estos preceptos es perfectamente diferente al previsto en el art. 155 y por consiguiente no ha lugar a invocar aquellos artículos de la Ley orgánica 2/1986 para impugnar la sustitución de los Mossos d'Esquadra. La coerción estatal del art. 155 establece una solución excepcional para supuestos extraordinarios que no están especialmente previstos en la ley.

${ }^{14}$ Con el fin de evitar un conflicto en la defensa de los intereses del Estado y de la Comunidad Autónoma de Cataluña, se suspende el plazo para que el Gobierno de Cataluña pueda personarse y formular alegaciones, en tanto el Consejo de Ministros, de conformidad con el art. 5 del Real Decreto 944/2017, de 27 de octubre, ejerza las funciones y competencias que corresponden al Consejo de Gobierno de la Generalitat de Catalunya.

${ }^{15} \mathrm{~N} .{ }^{\circ}$ de asunto $5884 / 2017$. 
No tiene sentido sostener que las medidas de carácter excepcional que se pueden aplicar conforme al art. 155 deben limitarse a las de mera organización, tanto más cuanto que ya están establecidas en leyes de carácter ordinario como es la ley de Seguridad.

\section{EL DICTAMEN 14/2017 DEL CONSELL DE GARANTIES ESTATUTÀRIES. EL RECURSO DE INCONSTITUCIONALIDAD DEL PARLAMENTO DE CATALUÑA}

Este Dictamen 14/2017 fue emitido a petición de tres diputados integrantes del Grupo Parlamentario de Junts pel Sí y miembros de la Diputación Permanente del Parlamento de Cataluña, como requisito previo ex arts. 76.3 E.A.C. y 16.2.a L.C.G.E. para instar un recurso de inconstitucionalidad frente al Acuerdo del Senado de 27 de octubre de 2017. Responde al antecedente del anterior Dictamen $13 / 2017$.

El objeto del Dictamen abarca no solo el Acuerdo del Senado, sino también los Reales Decretos (del 942/2017 al 946/2017) de ejecución del Acuerdo que se publicaron a continuación y con la misma fecha porque el conjunto constituye una unidad normativa susceptible de recurso de inconstitucionalidad (ATC 7/2012, FJ 3; STC 83/2016, FJ 9)

El Dictamen formula tres conclusiones:

A) La primera es la constitucionalidad de la medida A por la que se atribuye al Presidente del Gobierno del Estado la competencia para disolver el Parlamento y convocar elecciones en el plazo de seis meses, si bien se formulan dos votos particulares.

El Dictamen advierte de una falencia formal en el requerimiento del Presidente del Gobierno central: habría omitido especificar las medidas que se aplicarían en el supuesto de que la Comunidad Autónoma no rectificase el incumplimiento denunciado. Esta omisión no sería la más respetuosa, idónea y coherente con el principio constitucional de la autonomía y la excepcionalidad del art. 155. En opinión del Consell, habría resultado más deferente con la autonomía catalana que el Presidente del Gobierno central hubiese especificado que asumiría la facultad de convocar elecciones solo de manera subsidiaria.

El Consell reconoce que la medida de la disolución del Parlament difícilmente podría haber sido gradual o parcial. Sugiere la alternativa de una suspensión por seis meses del Parlamento de Cataluña, incluso sin interferencias ni control de su función legislativa, que habría mantenido a la cámara constituida pero con sus funciones restringidas. De este modo, el sistema institucional del autogobierno y el régimen parlamentarista de la 
Constitución (art. 152) y el Estatuto (arts. 55, 67 y 74) habrían permanecido respetados aunque bloqueados. Esta medida hubiese devenido la opción menos lesiva y proporcionada para la autonomía catalana y la más propicia para una pronta recuperación del normal funcionamiento del Parlamento y las demás instituciones de la Generalitat. Sin embargo, la realidad es que el RD 946/2017 aprobó la disolución del Parlamento y la inmediata convocatoria de elecciones

El voto particular de Jaume Vernet y Margarida Gil aduce que la discrecional atribución al Presidente del Gobierno central de la competencia para disolver el Parlamento y convocar elecciones vulnera el bloque de constitucionalidad, particularmente la Constitución en sus arts. 2 y 152 y el Estatuto en sus arts. 56, 66 y 75 que regulan el sistema parlamentarista de gobierno. Insisten en denunciar la ausencia de garantías y la falencia de que el requerimiento del Presidente del Gobierno central omitiese especificar las medidas que se aplicarían en el supuesto de ausencia de rectificación. No cumpliría ni el principio de proporcionalidad, ni el de gradualidad, ni el de temporalidad. Para los discrepantes se trata de una medida con un vicio constitucional de origen que no puede subsanarse por razones de oportunidad.

B) La segunda (por unanimidad) es la constitucionalidad de las medidas D.2 (Inaplicabilidad de las funciones parlamentarias de control e impulso del Gobierno previstas en el Reglamento del Parlament. Atribución de las funciones de control a la Comisión conjunta General de las Comunidades Autónomas y Constitucional) y D.3 (Sujeción de las propuestas de resolución del Parlament al contenido del Acuerdo del Senado).

La sustitución transitoria de las autoridades catalanas por las estatales comporta necesariamente que éstas limiten sus actuaciones a las de mero trámite hasta la constitución del nuevo Parlamento. «De acuerdo con lo anterior y únicamente en estos restringidos términos... puede entenderse que las autoridades provisionales permanezcan exentas del control parlamentario ordinario»

C) Y la tercera (por mayoría) es la inconstitucionalidad de la medida A (cese del Presidente de la Generalitat y demás miembros de su Gobierno) por vulnerar los principios de gradualidad, proporcionalidad, además de resultar innecesaria atendida la disolución del Parlamento. Consta un voto particular del consejero D. Carles Jaume.

El Consell enumera dos razones para sostener la inconstitucionalidad de esta medida que considera la más severa del Acuerdo del Senado.

En primer lugar sostiene que es una medida innecesaria tras que el Presidente del Gobierno central hubiese convocado elecciones dentro del breve plazo que marca el art. 75 del Estatuto (entre 40 y 60 días).

$\mathrm{Y}$ en segundo lugar mantiene que se trata de una medida con características sancionadoras, falta de proporcionalidad y gradualidad que podría haberse 
sustituido por otras menos invasivas de la autonomía, tales como la suspensión parcial de funciones (STC 215/2016, FJ 10.b) que permitiese su posterior revocación.

El voto particular de Carles Jaume parte del carácter extraordinario, excepcional, especial y provisional del art. 155. Añade que en su opinión, el cese del Presidente y demás miembros del Gobierno se ajusta a los requisitos de idoneidad porque desplazan a los titulares de los órganos que adoptaron las acciones lesivas; de especificidad porque son las decisiones necesarias y suficientes; y de proporcionalidad porque son medidas coherentes y lógicas. Concluye que sería ilógico encomendar la restitución del orden constitucional precisamente a quienes lo vulneraron.

Tal vez merezca destacar que el diferente origen gubernamental o parlamentario del nombramiento de los consellers que componen el Consell de Garanties Estatutàries no parece haber condicionado la opinión de sus integrantes. En efecto, el art. 77 del Estatuto regula el procedimiento de elección de los miembros del Consell. Dos tercios de sus ocho miembros son nombrados a propuesta del Parlamento por mayoría de tres quintos de los diputados; y el otro tercio por el Gobierno. Incluso las conclusiones favorables a la constitucionalidad de las medidas A y D2 fueron refrendadas también por consellers que habían sido propuestos por gobiernos nacionalistas. Las discrepancias y los argumentos más próximos a las tesis pro independentistas provienen de Margarida Gil, de elección gubernamental, pero también de Jaume Vernet, de elección parlamentaria.

Me parece especialmente destacable la diferencia de tono literario entre este Dictamen del Consell de Garanties Estatutàries y las Sentencias del Tribunal Constitucional sobre el procés independentista. Se trata de una cuestión relevante. La gravedad con que el Tribunal Constitucional narra los hechos está muy alejada del tono académico que usa el Consell de Garanties Estatutàries. Claro está que el Parlamento y el Gobierno catalanes no habían manifestado un especial respeto por el Tribunal al que llegaron a negar legitimidad.

La STC 259/2015 constituye un precedente de todas las demás que la sucedieron. Su objeto fue la Declaración del Parlamento de Cataluña 1/XI. El Parlamento catalán llega a retar con desobedecer las decisiones del Estado español en general y en particular las del Tribunal Constitucional.

La contumacia en la desobediencia no cesó. El Parlamento de Cataluña aprobó le Ley 19/2017 de 6 de septiembre, del referéndum de autodeterminación y la Ley 20/2017 de 8 de setiembre, de transitoriedad jurídica y fundacional de la República, hasta la Declaración unilateral de Independencia del 21 de octubre de 2017.

Quien va a resolver el recurso de inconstitucionalidad del Acuerdo del Senado de 27 de octubre de 2017 es precisamente ese Tribunal Constitucional al que las instituciones catalanas manifestaron desacato. 
Especial interés merece el voto particular de los consellers Jaume Vernet y Margarida Gil a la segunda conclusión del Dictamen así como la tercera conclusión sobre la inconstitucionalidad del cese del Gobierno. En mi opinión, la cuestión que suscitan constituye el verdadero problema constitucional del art. 155. El Tribunal Constitucional deberá resolver si la discrecionalidad política con que el art. 155 faculta al Gobierno y al Senado incluye la facultad de disolver al Parlamento y cesar al Gobierno autónomo o, por el contrario, está limitada por el art. 152 de la Constitución y los Estatutos de Autonomía.

La STC 215/2014 constituirá, en mi opinión, un precedente al que se atendrá el Tribunal. Aquella sentencia resolvió el recurso de inconstitucionalidad instado por el Gobierno canario frente a la Ley orgánica 2/2012 de estabilidad presupuestaria y sostenibilidad financiera. Ya entonces el pleno del Tribunal argumentó:

No cabe duda de que el recurso a la vía prevista en el art. 155 CE supone una injerencia clara en la autonomía financiera de las Comunidades Autónomas que lleva a una actuación subsidiaria del Estado, pero se trata de una injerencia autorizada por el propio texto constitucional, como reacción última a un incumplimiento flagrante de las obligaciones constitucionalmente impuestas.

Si el supuesto del incumplimiento flagrante de las obligaciones constitucionalmente impuestas (por el propio Tribunal) a las instituciones catalanas posibilita la actuación del Estado y la injerencia en las facultades autonómicas, cabe vaticinar una resolución acorde. Es patente el carácter extraordinario de la situación. Las instituciones catalanas tensaron al máximo el conflicto y la alegación del Presidente de la Generalitat invocando que había suspendido la aplicación de la DUI no parece contra argumento suficiente.

La interpretación discrepante del Consell invoca los principios de proporcionalidad, gradualidad y temporalidad. La proporcionalidad enfrenta tres magnitudes: la de la medida discutida, la de la medida alternativa y la del resultado pretendido. Tanto el prof. Vernet en relación a la disolución del Parlamento como el Consell por lo que se refiere al cese del Gobierno sostienen que otras medidas alternativas habrían resultado suficientes: La suspensión parcial de funciones del Gobierno o simplemente la convocatoria de elecciones dentro del breve plazo que marca el art. 75 del Estatuto (entre 40 y 60 días).

Sin duda que, comparadas con las adoptadas, estas medidas alternativas resultan menos invasivas. Sin embargo la cuestión es otra y obliga a responder a la pregunta de cuáles eran las medidas adecuadas para el objetivo de restituir el orden constitucional; y si hubiese resultado coherente que el Gobierno hubiese mantenido en sus cargos a quienes acusados de vulnerar el orden constitucional, fueron posteriormente procesados por los delitos de desobediencia (Código Penal, arts. 327.b y 556) malversación de fondos públicos (Código Penal arts. 432 a 435), resistencia y desobediencia a la autoridad (Código Penal, art. 550), usurpación de funciones (Código Penal, arts. 506 y 508), prevaricación (Código Penal, arts. 404 a 406), sedición (Código Penal, arts. 544 a 549) y rebelión (Código Penal, arts. 472 a 484). 
Este Dictamen es el principal fundamento del recurso de inconstitucionalidad instado por el Parlamento de Cataluña con fecha 8 de enero de 2017 y firmado por el Letrado Joan Ridau Martín ${ }^{16}$.

Su objeto afecta no solo al Acuerdo del Senado, sino también a todas las posteriores disposiciones reglamentarias dictadas por el Gobierno porque las resoluciones que dicta el Gobierno cuando actúa como un órgano político no son meramente administrativas y porque el total conjunto constituye una unidad normativa susceptible de recurso de inconstitucionalidad (ATC 7/2012, FJ 3; STC 83/2016, FJ 9)

El recurso argumenta sobre la legitimación activa de la Generalitat, el Parlamento de Cataluña y su Diputación Permanente. Tampoco esta cuestión debería generar controversia. El art. 162.1.a C.E. legitima a los órganos ejecutivos y legislativos de las Comunidades Autónomas y el art. 32.2 L.O.T.C. constriñe esta legitimación a que la ley o disposición con fuerza de ley afecte al ámbito de autonomía del recurrente. La STC 199/1987 perfiló que esta legitimación de las Comunidades Autónomas se extiende a todos aquellos supuestos en que exista un punto de conexión material entre la ley estatal y el ámbito competencial autonómico. No parece discutible que el Acuerdo del Senado recurrido afecta a la Generalitat de Cataluña y, por consiguiente, tampoco lo debe ser su legitimación activa para instar el recurso.

A continuación, el recurso aborda la cuestión de legitimación del Parlamento de Cataluña (disuelto por aplicación del Acuerdo del Senado ex art. 155) y su Diputación Permanente, conforme al precedente pro actione del ATC 547/1989. El art. 2.2 E.A.C. establece que corresponde a la Diputación Permanente el ejercicio de las facultades del Parlamento durante sus períodos de inactividad; y, entre ellas, según el art. 74.2.f R.P.C., ejercer las facultades parlamentarias en materia de constitucionalidad y conflictos de competencia. Así pues, por estar disuelto, el Parlamento no puede ejercer la propia facultad de acordar la interposición de recursos de inconstitucionalidad tal y como le atribuye el art. 174.1 R.P.C. y, en consecuencia, esta facultad se transfiere a la Diputación Permanente.

El recurso hace suyas las objeciones formuladas por el Dictamen del Consell de Garanties Estatutàries. Parte de ciertos argumentos de Derecho comparado: advierte de la diferencia entre la coerción estatal en el federalismo cooperativo alemán y en el sistema de reparto competencial propio del bloque de la constitucionalidad español.

\footnotetext{
16 Admitido a trámite por Providencia de 7 de febrero de 2018.

Con posterioridad al cierre de este trabajo, el Sindic de Greuges presentó su informe 2017 al Parlament (http://www.sindic.cat/site/unitFiles/5012/Informe\%20al\%20Parlament\%202017\%20 cat.pdf) en el que se muestra próximo a las posiciones del recurso: sostiene que la judicialización de la política está produciendo vulneraciones de derechos como el de expresión, reunión y manifestación; que los ilícitos políticos cometidos por instituciones catalanas no deberian ser confrontados con desproporción penal ni con prisión; y en particular que la intervención financiera de la Generalitat, la aplicación del artículo 155 y los recursos del Estado al TC contra leyes catalanas de contenido social han comportado perjuicios en las políticas y en los derechos sociales.
} 
Según el art. 37 de la Ley Fundamental de Bonn, la Federación puede obligar a un Land a cumplir los deberes federales porque las competencias de los Länder derivan de la delegación del Gobierno federal. Resulta diferente el sistema constitucional español porque el cuadro competencial de las Comunidades Autónomas incluye no solo facultades ejecutivas de la normativa estatal, sino además, competencias exclusivas y compartidas, es decir no delegadas.

Con carácter previo, sostiene que las medidas que el Gobierno podría adoptar deben estar presididas por los principios de «gradualidad», es decir han de ser posteriores a que se hayan agotado todos los medios preventivos; de "proporcionalidad», mediante un examen de necesidad y adecuación; y de «temporalidad», no solo en el sentido de limitación temporal, sino también de probibición de efectos irreversibles y pro futuro.

a) Sobre el requerimiento previo que el art. 155 establece como requisito previo: Se impugna tanto ad limine porque se habría omitido especificar el detalle de las medidas que se aplicarían en el supuesto de que la Generalitat no rectificase el incumplimiento denunciado; como a posteriori porque la contestación hipotética y retórica del Presidente de la Generalitat no puede considerarse como una justificación válida, fehaciente e indubitada del supuesto de hecho (la declaración unilateral de independencia) habilitante del art. 155 .

Es un argumento repetido en el recurso instado por UNIDOS-PODEMOS: tanto el preceptivo requerimiento del Gobierno central como el posterior Acuerdo del Senado concretan el incumplimiento denunciado en el hecho de que la Generalitat habría declarado unilateralmente la independencia y anunciado un posterior proceso constituyente. En sus dos contestaciones del 16 y del 19 de octubre, el Presidente de la Generalitat reiteró la suspensión de la declaración unilateral de independencia y, por consiguiente, no habría lugar a cumplimentar ni el objeto del requerimiento ni la finalidad del mismo. No podría considerarse que el Presidente de la Generalitat habría rechazado un requerimiento que se fundamenta en un incumplimiento de la Constitución que las instituciones autonómicas niegan haber realizado; y, por otra parte, el Presidente Puigdemont habría ofrecido la medida alternativa y preventiva del diálogo político entre los dos gobiernos. En el mismo sentido, el recurso denuncia la negativa del Senado a aceptar la intervención en el Pleno de Ferran Mascarell, Delegado de la Generalitat en Madrid, ex art. 189.3 R.S. (designación de representante a los efectos de remitir antecedentes, datos y alegaciones). La conclusión de la recurrente es que las instituciones del Estado habrían vulnerado el R.S. art. 189.1 que exige del Gobierno que justifique el incumplimiento grave y lesivo por la Comunidad Autónoma del requerimiento cursado, y art. 189.3 por la resolución de la Mesa de la Comisión al rechazar la intervención de D. Ferran Mascarell. 
b) Sobre las medidas adoptadas en el Acuerdo del Senado: Una interpretación gramatical, semántica y teleológica del art. 155.2 no debería permitir que el Gobierno y el Senado adopten medidas que comporten la suspensión del régimen autonómico o una alteración del modelo de reparto competencial establecido en el bloque de constitucionalidad al modo de la direct rule aplicada en el Ulster desde 1988 hasta el 2007. Añade que la suspensión del Estatuto de Autonomía mediante un real decreto transgrede el principio constitucional de jerarquía normativa. Y denuncia tanto las medidas que afectan al Ejecutivo de la Generalitat como al Parlamento.

La recurrente impugna el cese y sustitución del Presidente de la Generalitat y su Gobierno por ser contrarias a la Constitución, arts. 2, 23, 24, 147 y 152 y al Estatuto de Autonomía, arts. 67, 68 y 70. Defiende que constituye una doble vulneración de la autonomía política de la Generalitat (SSTC 25/1981, 32/1981) y del régimen parlamentario. La sustitución del Presidente y su Gobierno quebraría el principio de representatividad que establece que estos nombramientos resulten de la decisión electoral de los ciudadanos de la Comunidad y la confianza del Parlamento, con derecho de permanecer en los cargos salvo por las causas especialmente tasadas en la Ley.

Tampoco el Acuerdo superaría un test de proporcionalidad entre la coerción estatal y la finalidad de impedir la declaración unilateral de independencia y un posterior proceso constituyente, tanto más cuanto que son actuaciones que han sido anuladas o suspendidas. Más bien parecería una injustificable «sanción» a los miembros del Gobierno de la Generalitat en la que no se concreta el alcance de la punición.

Por otra parte, estos ceses implicarían la pérdida del aforamiento (art. 70.2 E.A.C.) que comportaría una vulneración del derecho al juez ordinario predeterminado por la ley y, por ende, del derecho a la tutela judicial efectiva del art. 24 C.E., además del ius in officium ex art. 23.2 C.E. a continuar en el cargo público salvo las causas de cese tasadas en los arts. 67.7, 68.4 E.A.C. y 7, 17.1 de la Ley catalana $13 / 2008$.

El recurso demanda la inconstitucionalidad de otras tres medidas del Acuerdo. De un lado, el apartado $B$ en el que se establece que entre las directrices que el Gobierno central puede dictar para la Administración de la Generalitat se incluye la de establecer un régimen de comunicación o autorización previa de sus actuaciones. En opinión de la recurrente, se trata de una tutela inaceptable, contraria a los principios de legalidad, seguridad jurídica y jerarquía normativa porque vulneraría el régimen de adopción de acuerdos previsto en los arts. 13 y ss. de la Ley catalana 26/2010 de régimen jurídico y de procedimiento de las administraciones públicas de Cataluña. De otro lado, en el apartado E del Acuerdo se prevé la nulidad de pleno derecho de disposiciones, actos y resoluciones autonómicos que contravengan el Acuerdo del Senado. Para los recurrentes el procedimiento del art. 155 no es propiamente legislativo y por consiguiente, el Acuerdo del Senado no puede sustituir la función que corresponde al art. 47 de la Ley 39/2015 de Procedimiento administrativo común so 
pena de vulnerar el principio de legalidad del art. 65 E.A.C. y el principio de seguridad jurídica del art. 9.3 C.E. (SSTC 27/1981, 46/1990, 179/1989). La tercera medida del apartado C que contempla la sustitución de los Mossos d'Esquadra por las Fuerzas y Cuerpos de seguridad del Estado supone, según la recurrente, una vulneración de la competencia compartida conforme a la C.E. arts. 149.1.29, 148.1.22 (STC 154/2005) y a Ley catalana 10/1994 Policia de la Generalitat-Mossos d'Esquadra.

Sobre las medidas referidas al poder Legislativo de la Generalitat, el recurso impugna, por ausencia de previsión constitucional expresa, la posibilidad del Presidente del Gobierno de acordar la disolución del Parlamento de Cataluña y convocar elecciones autonómicas (apartado A). Así mismo, en su defecto, mientras continuase vigente la legislatura, el Acuerdo establece la prohibición de celebrar un debate de investidura y la inaplicabilidad de las funciones del control del Gobierno previstas en el Reglamento del Parlamento sobre las comisiones de investigación (arts. 66 y 67) y la limitación del contenido de las propuestas de resolución (apartado D). Argumenta el recurrente que estas medidas vulnerarían el derecho a la participación electoral que regula la Constitución en sus arts. 23.1 y 23.2 además de la L.O.R.E.G. La atribución al Presidente del Gobierno central de la facultad de disolver el Parlamento de Cataluña y convocar elecciones autonómicas atentaría a la forma parlamentaria de gobierno de las Comunidades Autónomas (arts. 23.2, 151, 152 C.E.; 55, 67, 74, 75 E.A.C.). Añade que la actividad parlamentaria no es suplantable; no puede tener más límites que los establecidos en la Constitución, el Estatuto y el Reglamento; y tanto si es de impulso legislativo como si es deliberativa (STC 42/2014) está sujeta a control de constitucionalidad. Y concluye:

"Con ello, el Acuerdo del Consejo de Ministros culmina la suspensión en toda regla de la autonomía de Cataluña, ya que no solo se cesa al Gobierno, sino que se sitúa a la Administración bajo su dependencia y, si bien se mantiene formalmente al Parlamento, lo sitúa en una posición de subordinación jerárquica con relación al Gobierno de Estado.»

Reitero que coincido con el argumento que han sostenido el prof. Vernet en su voto particular al Dictamen del Consell de Garanties Estatutàries y los profs. Vintró y Ridau en las redacciones de sus respectivos recursos: Habría resultado más respetuoso con los principios de gradualidad y temporalidad pero, sobre todo con la autonomía catalana que, en el requerimiento, el Presidente del Gobierno hubiese especificado que asumiría la facultad de disolver el Parlamento solo de manera subsidiaria para el supuesto de que no lo acordase el propio Presidente de la Generalitat. Y ello no obstante, a mi entender, el Tribunal Constitucional no fallará por este motivo la inconstitucionalidad del Acuerdo del Senado. Ni el art. 155 C.E. ni el art. 189 R.S. prevén la limitación de que el Gobierno haya de advertir a la Comunidad Autónoma requerida las medidas que ha de proponer al Senado. Son dos trámites procesales sucesivos con diferentes destinatarios. Sobre todo, no parece responder a la ratio legis del precepto que el Presidente del Gobierno estuviese obligado a especificar las medidas antes de conocer la respuesta de la Comunidad Autónoma. La finalidad de la 
coerción estatal del art. 155 es que la Comunidad Autónoma rectifique como consecuencia de la simple denuncia del incumplimiento o del grave atentado al interés general y no de la amenaza del listado de medidas coercitivas. Solo en el caso de que el Presidente autonómico negase la rectificación y permaneciese en su decisión de incumplir la norma constitucional, procederá la comunicación de las medidas coercitivas.

A diferencia del recurso de inconstitucionalidad instado por UNIDOS-PODEMOS, el Suplico del recurso interpuesto por el Parlamento de Cataluña no incluye petitums subsidiarios. Demanda que se declare la inconstitucionalidad del Acuerdo del Senado y de todas las disposiciones que se han dictado, sin solución de continuidad, en desarrollo, complemento o adición, por constituir una unidad normativa.

\section{LA CUESTIÓN MATERIAL: ¿CONSTITUYE EL BLOQUE DE CONSTITUCIONALIDAD UN LÍMITE AL ART. 155? EXTRAPOLAR LA DOCTRINA DE LA DISCRECIONALIDAD DEL GOBIERNO EN EL ART. 86 C.E.}

Este interrogante es la alegación fundamental de los dos recursos al Acuerdo del Senado y, por consiguiente, debería ser el principal objeto de la Sentencia del Tribunal Constitucional.

Ambos recurrentes sostienen que una interpretación gramatical y teleológica del art. 155.2 debería prohibir que el Gobierno y el Senado aprueben medidas que comporten la suspensión del régimen autonómico o una alteración del modelo de reparto competencial establecido en el bloque de constitucionalidad.

En los dos recursos se insiste en que el cese del Presidente de la Generalitat y su Gobierno constituye una vulneración del bloque de constitucionalidad, el principio de autonomía y el reparto competencial que regulan particularmente la Constitución arts. 2, 23, 24, 147 y 152 y el Estatuto de Autonomía, arts. 56, 66, 67, 68, 70 y 75. Según los recurrentes, la medida presentaría vicios de constitucionalidad invalidantes e insubsanables más allá de que se invoque el principio de oportunidad política ex art. 155. Ambos recursos coinciden en denunciar la ausencia de garantías y la falencia de que el requerimiento del Presidente del Gobierno central omitiese especificar las medidas que se aplicarían en el supuesto de ausencia de rectificación por parte de la Comunidad Autónoma requerida.

Ni el art. 155 de la Constitución ni el art 189 del Reglamento del Senado sujetan la validez del requerimiento a que el Gobierno enumere las medidas correctoras que ha de proponer a la aprobación del Senado. Son dos trámites sucesivos distintos dirigidos uno al Presidente autonómico y otro al Senado. Pero existe un argumento mucho más rotundo para contradecir el argumento de los recurrentes. No puede exigirse del Gobierno que relacione las medidas ex art. 155 antes de conocer la res- 
puesta de la Comunidad Autónoma interpelada. El art. 155 está previsto para resolver el supuesto de hecho de una Comunidad Autónoma que incumple la Constitución de forma grave y contumaz. El primer objetivo del art. 155 no es el de aplicar medidas coercitivas sino que la Comunidad Autónoma rectifique y esta es la perspectiva desde la que debe interpretarse el art. 155. La Comunidad Autónoma requerida por incumplir el orden constitucional o atentar gravemente al interés general debería rectificar de buen grado a resultas del requerimiento del Gobierno y no como consecuencia de la amenaza de un listado de medidas coercitivas. La coerción es la última ratio y no ha lugar a desvelarla hasta que la Comunidad Autónoma niegue la rectificación. Jamás antes, tanto más cuanto que la respuesta de la Comunidad Autónoma puede condicionar en más o en menos las medidas coercitivas necesarias.

La demanda de inconstitucionalidad de los recurrentes se centra en aquel argumento estructural: el Acuerdo conllevaría una doble vulneración de la autonomía política de la Generalitat (SSTC 25/1981, 32/1981) y del régimen parlamentario regulado en la Constitución, el Estatuto y la L.O.R.E.G. La sustitución del Presidente y su Gobierno quebraría el principio de representatividad que establece que estos nombramientos resulten de la decisión electoral de los ciudadanos de la Comunidad y la confianza del Parlamento, con derecho de permanecer en los cargos salvo por las causas especialmente tasadas en la Ley. Una y otra vez insisten en invocar el debate constituyente y en apelar a la auténtica voluntad de los constituyentes para recordar el rechazo al voto particular que defendió Manuel Fraga Iribarne y a dos enmiendas del diputado José M. Ortí Bordás y del senador Alberto Ballarín Marcial, ambos de la U.C.D., propugnando la introducción de sendos apartados que previesen la suspensión de los órganos autonómicos y el nombramiento de un Gobernador general. Resulta inconsistente sostener que la coerción estatal tal y como aparece recogida en el amplísimo texto del art. 155 no alcanzaría para suspender y sustituir a los órganos autonómicos. De hecho, los recurrentes introducen un forzado y obsoleto argumento originalista que parece tomado de Robert Bork en su debate con Ronald Dworkin ${ }^{17}$.

Añaden que la medida impugnada atentaría a los principios de proporcionalidad, de gradualidad y de temporalidad. Sostienen que se trataría de una medida innecesaria que podría haberse sustituido por otras menos invasivas de la autonomía, tales como la suspensión parcial de funciones (STC 215/2016, FJ 10.b) que permitiese su posterior revocación, tanto más cuanto que el Presidente del Gobierno central convocó elecciones al Parlament de Cataluña dentro del breve plazo que marca el art. 75 del Estatuto.

Los recurrentes llegan a admitir que el art. 155 habilita al Estado para suspender y sustituir competencias ordinarias de una Comunidad Autónoma, siempre que la sustitución se contraiga al ejercicio de aquellas atribuciones cuya suspensión resulte imprescindible (STC 185/2016 sobre el art. 92 LOTC). Ahora bien, esta sustitución

17 Miguel BELTRÁN DE FELIPE (1989), Originalismo e interpretación. Dworkin vs Bork una polémica constitucional, Ed. Civitas, Madrid. 
debería atenerse a ciertos límites: La sustitución implica un cambio temporal de la autoridad, sin afectar a sus mecanismos de control, con expresa concreción de la finalidad y el objeto. La finalidad de la sustitución habrá de constreñirse a la restauración del orden constitucional. El objeto, deberá limitarse a las decisiones ejecutivas pero en ningún caso a actuaciones parlamentarias o gubernamentales de libre decisión.

La Doctrina es unánime en resaltar el carácter extraordinario y temporal del art. 155. Su aplicación está prevista para un escenario de confrontación política entre altos órganos del Gobierno del Estado y una Comunidad Autónoma, ambos con representatividad democrática. Se aprobó con un texto tan inconcreto que las facultades del Gobierno carecen de un límite expreso. Ahora bien, como en tantos otros Estados compuestos, la ratio legis del precepto es la de atribuir poderes al Gobierno para forzar la obediencia de una Comunidad Autónoma reticente a cumplir con el Ordenamiento constitucional. Es una última ratio tras que la constitutional conversation entre los órganos discrepantes hubiese devenido ineficaz para resolver el conflicto.

La activación de la coerción estatal del art. 155 es consecuencia de la reiterada desobediencia de las instituciones catalanas. Desoyendo todas las sentencias del Tribunal Constitucional, el Parlamento de Cataluña aprobó sendas leyes de convocatoria de un referéndum de autodeterminación y de proclamación de la República. El procés llegó a la Declaración unilateral de independencia y a ella se refiere el requerimiento del Presidente del Gobierno. Los recurrentes contra argumentan la ausencia del requisito de la gravedad porque las leyes habrían sido declaradas inconstitucionales por el Tribunal Constitucional y el Presidente de la Generalitat habría contestado el requerimiento dando cuenta de la suspensión de los efectos del mandato popular resultante del referéndum de autodeterminación convocado para el1 de octubre y ofreciendo a cambio un diálogo bilateral.

La apreciación por el Gobierno de que el incumplimiento denunciado fue grave responde a todas las Sentencias del Tribunal Constitucional desde la n. ${ }^{\circ}$ 259/2015. Es de esperar que el Tribunal mantenga su criterio sobre la gravedad del incumplimiento enjuiciado. Efectivamente el objeto y la finalidad del requerimiento es la declaración unilateral de independencia pero adviértase que el Presidente de la Generalitat respondió no ya reconociendo su «revocación» sino solo su «suspensión». Se trata de una circunstancia harto relevante que contradice la argumentación de los recurrentes cuando afirman que no puede considerarse rechazado un requerimiento que se basa en un incumplimiento que las instituciones autonómicas niegan haber realizado. Antes al contrario, solo cabe suspender aquello que ya se inició y si se inició, se realizó. Se podrá replicar que solo se realizó un poco. Lo que será insostenible es mantener que no se realizó en absoluto.

La STC 259/2015 sobre la Declaración del Parlamento de Cataluña 1/XI estableció un precedente al que se han atenido todas las sentencias posteriores. En aquella Declaración, el Parlamento catalán llega a desafiar con desobedecer las decisiones del Estado español en general y en particular las del Tribunal Constitucional. Y puso en práctica su pulso al Estado. La contumacia en la desobediencia no cesó. El Parlamen- 
to de Cataluña aprobó la Ley 19/2017 de 6 de septiembre, del referéndum de autodeterminación y la Ley 20/2017 de 8 de setiembre, de transitoriedad jurídica y fundacional de la República, hasta la Declaración unilateral de Independencia del 21 de octubre de 2017.

Este es el escenario. La pregunta es si el bloque de constitucionalidad supone o no un límite expreso en las facultades coercitivas del Estado para obligar a que la Generalitat de Cataluña acate el cumplimiento del orden constitucional; si la discrecionalidad política con que el art. 155 faculta al Gobierno y al Senado incluye la facultad de disolver al Parlamento y cesar al Gobierno autónomo o está limitada por el art. 152 de la Constitución y los Estatutos de Autonomía. A mi entender, existen razones de hecho y de derecho para negar ese límite

Las razones de hecho se infieren del mismo recurso de UNIDOS-PODEMOS. Los 50 diputados de este grupo llegan a sostener que la aplicación del art. 155 no faculta al Gobierno del Estado para cesar al Gobierno de la Generalitat, sino solo para cursarle instrucciones. Pues bien, si así fuese, deberemos colegir que el art. 155 es un precepto ineficaz y meramente nominal. Carecería de todo sentido lógico que, para restaurar el orden constitucional, el Estado no tuviese otro mecanismo que el de encomendar esa tarea a la Comunidad Autónoma desobediente. Sería una interpretación absurda defender que la sofocación de la rebeldía se tuviese que comisionar precisamente a los insurrectos que han sido procesados por graves delitos de desobediencia. Y las interpretaciones absurdas deben ser ad radicem rechazadas ${ }^{18}$.

Las razones jurídicas obligan a determinar cuál es la discrecionalidad del Estado ex art. 155. ¿Cómo reglar la discrecionalidad política del Gobierno? ¿Cuáles son sus límites constitucionales? No existe jurisprudencia sobre el art. 155, de modo que el más detallado análisis que el Tribunal Constitucional ha elaborado de la discrecionalidad política del Gobierno se ha centrado en el art. 86 C.E. sobre los decretos-leyes. Esta Jurisprudencia introduce criterios genéricos que, en mi opinión, serán extrapolables a los recursos estudiados en el presente trabajo. Para el Tribunal, allá donde la Constitución se la atribuya, la discrecionalidad política del Gobierno implica su facultad para adoptar decisiones de forma autónoma, sin injerencias del Tribunal al que solo compete el control de los límites constitucionales de la actuación gubernamental. El Tribunal Constitucional expone un criterio teleológico y sostiene que los actos políticos del Gobierno están sujetos al límite de la conexión de sentido o relación de adecuación entre la situación explícita, razonada y definida que constituye el presupuesto babilitante y las medidas que se adoptan. Corresponde al Tribunal contrastar esa conexión mediante la valoración conjunta de todos aquellos factores que determinaron al Gobierno a dictar la disposición legal excepcional, su estructura y su contenido.

${ }^{18}$ Franciso J. EZQUIAGA GANUZA (1994): «Argumentos interpretativos y postulado del legislador racional» en Isonomía — Revista de Teoría y Filosofía del Derecho—. ITAM, México, n. ${ }^{\circ} 1$, octubre 1994, pp. 69 a 98: «...toda atribución de significado que implique poner en cuestión la imagen de racionalidad del legislador; cualquier interpretación que conduzca resquebrajar alguno de los atributos que se predican del legislador racional será considerada absurda y rechazada» 
Ponente de la STC 34/2017 de 20 de julio ${ }^{19}$, la Magistrada y profesora de la Universidad de Barcelona, Encarna Roca explica la vasta doctrina constitucional del art. 86 C.E. y el control externo por parte del Tribunal que habrá de verificar, pero no sustituir, el juicio político o de oportunidad que compete al Gobierno y argumenta:

"Generalmente, se ha venido admitiendo el uso del decreto-ley en situaciones que se han calificado como «coyunturas económicas problemáticas», para cuyo tratamiento representa un instrumento constitucionalmente lícito, en tanto que pertinente y adecuado para la consecución del fin que justifica la legislación de urgencia, que no es otro que subvenir a «situaciones concretas de los objetivos gubernamentales que por razones difíciles de prever requieran una acción normativa inmediata en un plazo más breve que el requerido por la vía normal o por el procedimiento de urgencia para la tramitación parlamentaria de las leyes» (SSTC 31/2011, de 17 de marzo (RTC 2011, 31), FJ 4; 137/2011, de 14 de septiembre (RTC 2011, 137), FJ 6, y 100/2012, de 8 de mayo, FJ 8)».

Este párrafo parece haber influido en la redacción de los antecedentes del Acuerdo que el Gobierno transmitió al Senado para la aprobación de las medidas del art. 155. Las reiteradas referencias a la excepcionalidad del momento político y económico que se leen en el Acuerdo tal vez tengan que ver con la doctrina sobre el presupuesto de hecho en los decretos leyes que también se lee en la STC 6/1983 de 4 de febrero, reiterada en las SSTC 182/1997 de 28 de octubre y237/2012 de 13 de diciembre, entre otras:

«... la utilización de este instrumento normativo (el decreto ley) se estima legítima en todos aquellos casos en que hay que alcanzar los objetivos marcados para la gobernación del país, que, por circunstancias difíciles o imposibles de prever, requieren una acción normativa inmediata o en que las coyunturas económicas exigen una rápida respuesta».

El Acuerdo del Senado explica la excepcionalidad económica y social del momento cuando en el apartado B se refiere al deterioro del bienestar social y económico o a la factura de convivencia. En razón a que este deterioro no se menciona en el requerimiento a la Comunidad autónoma, los recurrentes denuncian una supuesta incoherencia entre el requerimiento y el Acuerdo del Senado. Sin embargo, el Acuerdo no menciona que la solución a este deterioro sea un objetivo ex novo añadido a los propuestos por el Gobierno, sino como la descripción de una de las consecuencias del proceso soberanista de secesión que describe como una desobediencia rebelde sistemática y consciente de los reiterados pronunciamientos y requerimientos del Tribunal Constitucional, afectando de manera grave al interés general de España.

En suma, el Tribunal Constitucional limita la discrecionalidad de la actuación política del Gobierno al criterio teleológico de la finalidad constitucional pretendida. El control de constitucionalidad del Tribunal habrá de constatar que las medidas del

19 V. también SSTC 26/2016 18 de febrero, 329/2015 15 de diciembre, 96/2014 12 de junio, 237/2012 13 de diciembre, 68/2007 28 de marzo, 332/2005 15 diciembre, 182/1997 28 de octubre, $111 / 19832$ de diciembre. 
Gobierno responden a una situación política o económica difícil e imprevisible y a que existe una lógica conexión entre esa situación y las medidas que se adoptan, es decir que sean pertinentes y adecuadas para la consecución del fin previsto en la Constitución.

En su Dictamen, el Consell de Garanties Estatutàries insiste en argumentar la vulneración del principio de proporcionalidad porque el Gobierno habría podido obtener la finalidad constitucional pretendida, sin necesidad de cesar al Gobierno de la Generalitat, mediante la aplicación de otras medidas alternativas tales como la suspensión parcial de funciones del Gobierno o la convocatoria de elecciones. El principio de proporcionalidad obliga a contrastar la medida acordada en el Acuerdo del Senado con la alternativa a que se refieren los recurrentes y evaluar la eficacia de una y otra para el resultado pretendido. Claro está que, comparada con el cese del Gobierno autonómico, la suspensión parcial de sus funciones hubiese resultado una medida menos invasiva. Sin embargo, es obligado plantearse si para obtener el resultado de la restitución del orden constitucional hubiese sido preferible mantener a Carles Puigdemont en su cargo de Presidente de la Generalitat, aún con sus funciones parcialmente suspendidas, en lugar de cesarle.

El precedente de la STC 215/201 ${ }^{20}$ ofrece un indicio de la posible interpretación del Tribunal. En el recurso de inconstitucionalidad instado por el Gobierno canario frente a la Ley orgánica 2/2012 de estabilidad presupuestaria y sostenibilidad financiera, el pleno del Tribunal describió el art. 155 como la reacción última a un incumplimiento flagrante de las obligaciones constitucionalmente impuestas; y amparó una actuación subsidiaria del Estado que supusiese una injerencia clara en la autonomía financiera de las Comunidades Autónomas.

Pues bien, si este fuese el criterio también para la resolución de los recursos de UNIDOS-PODEMOS y el Parlamento de Cataluña a la aplicación del art. 155, el Tribunal Constitucional analizará la conexión entre la excepcionalidad y urgencia del presupuesto de hecho (el incumplimiento flagrante de las obligaciones constitucionalmente impuestas), las medidas aprobadas por el Senado (una injerencia en las competencias constitucionales y estatutarias de la Comunidad Autónoma de Cataluña) y la finalidad de la restauración del orden constitucional. La suspensión temporal del bloque de constitucionalidad no podría ser un obstáculo para la finalidad constitucional perseguida. Las competencias de la Generalitat, el sistema parlamentarista del Estatut y el principio de representatividad de los diputados y miembros del Gobierno no están por encima del principio de sujeción a la Constitución del art. 9.3. Carecería de sentido que con el pretexto de salvar el bloque de inconstitucionalidad, fuese la propia Constitución en su totalidad la que resultase fenecida en Cataluña. El art. 155 es un precepto de Derecho excepcional establecido para resolver problemas excepcionales. Su vocación es de temporalidad y su objeto afecta a situaciones en las que el ordenamiento constitucional está

${ }^{20}$ «No cabe duda de que el recurso a la vía prevista en el art. 155 CE supone una injerencia clara en la autonomía financiera de las Comunidades Autónomas que lleva a una actuación subsidiaria del Estado, pero se trata de una injerencia autorizada por el propio texto constitucional, como reacción última a un incumplimiento flagrante de las obligaciones constitucionalmente impuestas.» 
en un peligro grave por la contumaz desobediencia de una Comunidad Autónoma. No parece que el bloque de constitucionalidad deba prevalecer a riesgo de que desaparezca la Constitución misma, el orden constitucional en su integridad.

Para terminar: No se me oculta que tras la aplicación del art. 155 en la Comunidad catalana subyace un conflicto político. El encaje de Cataluña en el Estado es un problema con hondas raíces históricas. El prof. Pérez Royo ${ }^{21}$ es tal vez quien más ha insistido en determinar que el resurgimiento de este conflicto rebrotó con motivo de la Sentencia 31/2010 del Tribunal Constitucional que declaró inconstitucional una parte del Estatut que había sido previamente aprobado en referéndum por la población censada en Cataluña. Esta circunstancia habría quebrado el consenso que dio lugar a la Constitución de 1978. El difícil remiendo de este desencuentro exigirá, en mi opinión, la restauración del diálogo constitucional para alcanzar un nuevo consenso y su posterior plasmación en una reforma constitucional.

Ahora bien, el objeto de este trabajo sobre el art. 155 es otro y se constriñe al examen jurídico de las posturas de las partes personadas en los recursos de inconstitucionalidad instados frente al Acuerdo del Senado, la ponderación de los distintos argumentos y el vaticinio de cómo será la futura sentencia del Tribunal Constitucional.

\section{Title:}

Section 155 of the Spanish Constitution. The Order of the Spanish Senate of 27 th of October, 2017.

\section{Summary:}

1. The injuction of the Spanish Government and the Order of the Spanish Senate of 27th of October, 2017; 2. The application of the state coercion of section 155 in Catalonia; 3. The procedural question of the judicial review of the Order of the Senate; 4 . The motion filed by the political party Unidos-Podemos claiming that the application of section 155 is against the Spanish Constitution; 5. The Opinion 14/2017 of the Catalan Consell de Garanties Estatutáries. The motion filed by the Catalan Parliament for judicial review against the Order of the Spanish Senate; 6. The material question: Does the bloque de constitucionalidad entails a limit beforesection 155 ?

${ }^{21}$ Javier PÉREZ ROYO: «El primer estado de excepción de la democracia» en el diario digital Eldiario.es edición del 24 de noviembre de 2017. 


\section{Resumen:}

El art. 155 de la Constitución regula la coerción federal (federal coercion) con un texto inspirado en el art. 37 de la Ley Fundamental de Bonn, si bien presenta alguna importante diferencia, particularmente por la distinta configuración electoral del Senado y el Bundesrat. Su redacción es un ejemplo característico de la ambigüedad propia de los preceptos constitucionales; y su interpretación padece de que carece de desarrollo legislativo y precedentes históricos. Con su Resolución de 27 de octubre de 2017, el Senado ha aplicado por vez primera el art. 155 por entender que la Generalitat había incurrido en desobediencia a la Constitución. La autorización al Gobierno central conllevó el cese del Gobierno de Cataluña y la posterior disolución del Parlamento autonómico. Dos han sido los recursos de inconstitucionalidad instados, respectivamente, por el grupo parlamentario de Unidos-Podemos y por la Diputación Permanente del Parlamento de Cataluña. En este trabajo se aborda su análisis jurídico y se arriesga el vaticinio de Sentencia que habrá de dictar el Tribunal Constitucional.

\section{Abstract:}

Section 155 of the Spanish Constitution regulates federal coercion by means of a text inspired in section 37 of the Fundamental Law of Bonn, although the former presents some important differences, especially due to the different electoral configuration of the Spanish Senate and the Bundesrat. The wording of section 155 is a good example of the characteristic ambiguity of constitutional texts. Its interpretation suffers from a lack of legislative development and former precedents. By means of the Order of 27 th of October, 2017, the Spanish Senate has applied for the first time section 155, understanding that the Catalan Generalitat had violated the Constitution. The authorization given to the Spanish Government entailed the dismissal of the Autonomous Government of Catalonia and the dissolution of the Autonomous Parliament. Two motions have been filed, one by the parliamentary group Unidos-Podemos, and another by the $D i$ putación Permanenteof the Parliament of Catalonia. This paper tackles the legal analysis of section 155, and risks predicting the future ruling of the Spanish Constitutional Court.

\section{Palabras clave:}

Coerción estatal; ambigüedad constitucional; desobediencia; instituciones autonómicas; potestades discrecionales del Gobierno.

\section{Key words:}

Federal coercion; constitutional ambiguity; disobedience; autonomous institutions; discretionary government powers. 